Linköping Studies in Science and Technology

Dissertation No. 1933

\title{
Synthesis and characterization of Mo- and W-based atomic laminates
}

Rahele Meshkian

1.0 UNNIERTING

\author{
Materials Design \\ Thin Film Physics Division \\ Department of Physics, Chemistry, and Biology (IFM) \\ Linköping University \\ SE-581 83 Linköping, Sweden \\ Linköping 2018
}


The cover shows a schematic of delaminated $\mathrm{W}_{1.33} \mathrm{C}$ MXene with ordered divacancies, obtained after removal of the $\mathrm{Al}$ and $\mathrm{Sc}$ layers from the in-plane chemically ordered $i$-MAX phase $\left(\mathrm{W}_{2 / 3} \mathrm{Sc}_{1 / 3}\right)_{2} \mathrm{AlC}$.

(C) Rahele Meshkian

ISBN 978-91-7685-312-2

ISSN 0345-7524

Printed by LiU-Tryck, Linköping, 2018 


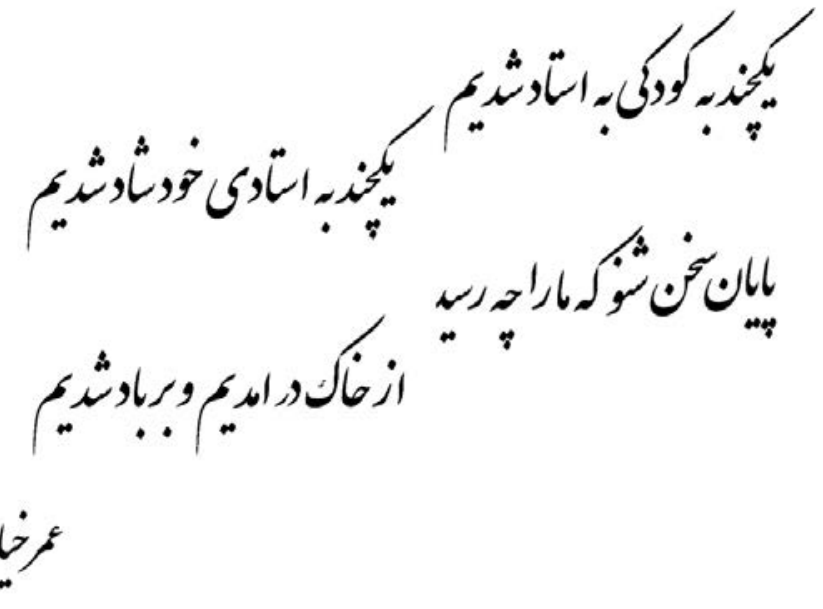

For a while, to a master we have gone

For a while, in our mastery we have flown

In the end, listen to what became of us

From dust we came, with wind we have gone

$O_{\text {mar }}$ Thayam 



\section{ABSTRACT}

$M_{n+1} A X_{n}$ (MAX) phases are inherently nanolaminated compounds based on transition metals $(M)$, A group elements $(A)$, and carbon or/and nitrogen $(X)$, which exhibit a unique combination of ceramic and metallic properties. My thesis work has focused on exploring novel MAX phase chemistries, including elemental combinations beyond those traditionally used for MAX phases, and their graphene-analogous 2D counterpart, MXenes.

The first part of the thesis investigates Mo-based MAX phases, which are among the least studied, despite indication of superconducting properties and potential for derivation of Mo-based MXenes. Initially, I performed theoretical calculations focused on evaluation of phase stability of the $\mathrm{Mo}_{n+1} \mathrm{GaC}_{n}$ MAX phases, and synthesized the predicted stable $\mathrm{Mo}_{2} \mathrm{GaC}$ in thin film form using DC magnetron sputtering. Close to phase pure epitaxial films were grown at $\sim 590{ }^{\circ} \mathrm{C}$, and electrical resistivity measurements using a four-point probe technique suggest a superconducting behavior with a critical temperature of $\sim 7 \mathrm{~K}$. The follow-up of this work, was synthesis of a new MAX related material, $\mathrm{Mo}_{2} \mathrm{Ga}_{2} \mathrm{C}$, also by means of DC magnetron sputtering. The theoretical predictions as well as the materials characterization by X-ray diffraction and neutron powder diffraction, suggested a Ga bilayer interleaved between a set of $\mathrm{Mo}_{2} \mathrm{C}$ blocks, arranged in a simple hexagonal structure.

It is known that selectively etching of the $A$-layer in a MAX phase, shown for $A=\mathrm{Al}$, can lead to realization of a MXene. Hence, the next step in my research was to explore the possibility of etching of $A=\mathrm{Ga}$ in $\mathrm{Mo}_{2} \mathrm{GaC}$ as well as in $\mathrm{Mo}_{2} \mathrm{Ga}_{2} \mathrm{C}$, targeting a $\mathrm{Mo}_{2} \mathrm{C}$ MXene, as motivated by theoretically proposed superior thermoelectric properties of this $2 \mathrm{D}$ material. While $\mathrm{Mo}_{2} \mathrm{GaC}$ did not allow removal of the $A$-layer, I showed that $\mathrm{Mo}_{2} \mathrm{C}$ MXene could be realized from etching $\mathrm{Mo}_{2} \mathrm{Ga}_{2} \mathrm{C}$ thin films, removing the Ga bilayer, in $50 \%$ hydrofluoric acid at a temperature of $\sim 50^{\circ} \mathrm{C}$ for a duration of $\sim 3 \mathrm{~h}$. Hence, the results did not only produce the first Mo-based MXene, it also showed that MXenes can be obtained for etching $A$-elements other than Al. This, in turn, increase the pathways for expanding the family of MXenes.

I thereafter set out to explore the magnetic properties resulting from Mn-alloying of the non-magnetic $\mathrm{Mo}_{2} \mathrm{GaC}$ MAX phase. For that purpose, $(\mathrm{Mo}, \mathrm{Mn})_{2} \mathrm{GaC}$ was synthesized using a DC magnetron sputtering system with $\mathrm{Ga}$ and $\mathrm{C}$ as elemental targets and a 1:1 atomic ratio Mo:Mn compound target. Heteroepitaxial films on $\mathrm{MgO}(111)$ substrates were grown at $\sim 530^{\circ} \mathrm{C}$, as confirmed by X-ray diffraction. Compositional analysis using energy dispersive 
X-ray spectroscopy showed a 2:1 ratio of the $M$ - and $A$-elements and a 1:1 ratio for the Mo and Mn atoms in the film. Vibrating sample magnetometry was utilized to measure the magnetic behavior of the films, showing a magnetic response up to at least $300 \mathrm{~K}$, and with a coercive field of $0.06 \mathrm{~T}$, which is the highest reported for any MAX phase to date.

The second part of my research has been dedicated to realizing new MAX phase related, chemically ordered compounds and their MXene derivatives, and to initiate exploration of their properties. Materials synthesis was performed by pressureless bulk sintering, and inspired by theoretical calculations we showed evidence for a new so called $o$-MAX phase, $\mathrm{Mo}_{2} \mathrm{ScAlC}_{2}$, with an out-of-plane chemically ordered structure. It is the first experimentally verified Sc-containing MAX phase, which makes its corresponding MXene, $\mathrm{Mo}_{2} \mathrm{ScC}_{2}$, also presented in this work, the first MXene including Sc. Moreover, I discovered two so called $i$-MAX phases including $\mathrm{W},\left(\mathrm{W}_{2 / 3} \mathrm{Sc}_{1 / 3}\right)_{2} \mathrm{AlC}$ and $\left(\mathrm{W}_{2 / 3} \mathrm{Y}_{1 / 3}\right)_{2} \mathrm{AlC}$, which display in-plane chemical ordering in the $M$-layer. Furthermore, both was shown to allow synthesis of their corresponding 2D counterpart; $\mathrm{W}_{1.33} \mathrm{C}$ MXene, with ordered vacancies. Initial test on these novel MXenes showed a high potential for hydrogen evolution reaction.

Altogether, I have in my thesis work realized 6 novel MAX phases and related materials, and have shown evidence for 4 new MXenes. These materials inspire a wide range of future studies, with respect to fundamental properties as well as potential for future applications. 


\section{POPULÄRVETENSKAPLIG SAMMANFATTNING}

MAX-faser är en familj av nanolaminerade material bestående av minst en övergångsmetall (M), ett atomslag från grupp A, oftast från grupp 13 och 14, i periodiska systemet (A), samt kol och/eller kväve (X). Dessa material uppvisar en kombination av både metalliska och keramiska egenskaper, vilket har inspirerat till många vetenskapliga studier under det senaste decenniet. Liksom metaller, har de bra ström- och värmeledningsförmåga, och på samma sätt som keramer, visar dessa motstånd mot oxidering och korrosion.

I detta arbete har jag studerat material inom denna familj genom att använda mig av både teoretiska beräkningar och experimentella metoder för att upptäcka och syntetisera nya MAX-faser som innehåller outforskade atomslag. Teoretiska beräkningar har genomförts för att förutsäga hur stabil en MAX-fas är med avseende på tävlande faser. Om den undersökta MAX-fasen verkar vara stabil i teorin, så är det motiverat att försöka syntetisera den fasen i labbet. Dessutom kan man med hjälp av teoretiska beräkningar även förutsäga vilka nya kombinationer av atomer, eller tillsatser av nya atomslag i en redan existerade MAX fas, som kan resultera till förbättrade eller helt nya egenskaper.

En av de viktigaste egenskaperna hos MAX-faser är att de kan ge upphov till så kallade MXener. Dessa bildas när A-lagret tas bort från MAX-fasen genom att materialet etsas i en syra. Det som kvarstår är två-dimensionella (2D) flak av materialet, liknande det välkända materialet grafén, vilket består av ett lager kol-atomer. MXener har visat sig vara mycket lovande kandidater för en stor mängd tillämpningar, t.ex. för energilagring, som elektrod i Lijon batterier eller i superkondensatorer. Nya teoretiska studier visar också att MXene-material kan användas för väteproduktion, som termoelektriskt material, o.s.v.

Materialsyntes har utförts på två olika sätt; genom magnetron sputtring, för att växa tunna filmer av önskade MAX faser, dvs. $\mathrm{Mo}_{2} \mathrm{GaC}, \mathrm{Mo}_{2} \mathrm{Ga}_{2} \mathrm{C},\left(\mathrm{Mo}_{0.5}, \mathrm{Mn}_{0.5}\right)_{2} \mathrm{GaC}$, och bulksyntes för att skapa $\mathrm{Mo}_{2} \mathrm{ScAlC}_{2},\left(\mathrm{~W}_{2 / 3} \mathrm{Sc}_{1 / 3}\right)_{2} \mathrm{AlC}$ och $\left(\mathrm{W}_{2 / 3} \mathrm{Y}_{1 / 3}\right)_{2} \mathrm{AlC}$. Bortsett från $\mathrm{Mo}_{2} \mathrm{GaC}$ är alla dessa faser helt nya och o-utforskade, och de har i sin tur gett upphov till 4 nya MXener, för första gången baserade på $\mathrm{Sc}, \mathrm{Mo}$, och W.

Syntes av $\mathrm{Mo}_{2} \mathrm{GaC}$ som en tunnfilm är motiverat av att få ett prov som är så rent som möjligt från tävlande faser, detta för att kunna utvärdera tidigare förslagna supraledande egenskaper hos denna MAX-fas. På samma sätt är ett prov av hög kvalité önskvärt för att kunna utvärdera magnetiska egenskaper hos $\left(\mathrm{Mo}_{0.5}, \mathrm{Mn}_{0.5}\right)_{2} \mathrm{GaC} . \mathrm{Mo}_{2} \mathrm{Ga}_{2} \mathrm{C}$ är en ny MAX-relaterad fas med två 
Ga-lager mellan block av MX, och både detta material och $\mathrm{Mo}_{2} \mathrm{ScAlC}_{2}$ har syntetiserats för att vi ska kunna skapa de första Mo-baserade MXenerna, och i sin tur undersöka deras egenskaper. På samma sätt har vi lyckats skapa de första MXenerna baserade på W, och har initierat studier för att utvärdera deras potential för väteutveckling. De första resultaten är lovande.

De nya materialen presenterade i denna avhandling motiverar till en mängd studier, några av dem redan initierade i flera nystartade projekt. Dessa studier fokuserar på både grundläggande egenskaper och materialens potential för tillämpningar. 


\section{PREFACE}

The presented thesis is a summary of my Ph.D. studies between spring 2013 and spring 2018, in the Materials Design Group, Thin Film Physics Division, Department of Physics, Chemistry and Biology (IFM), at Linköping University in Sweden. This work involves collaboration with Iceland University (Iceland), Drexel University (USA) and University of Duisburg-Essen (Germany).

Financial support has been provided by the Swedish Research Council (VR) and the Swedish Foundation for the Strategic Research (SSF).

Theoretical calculations were performed using supercomputer resources provided by Swedish National Infrastructure for Computing (SNIC) at the National Supercomputer Centre (NSC). 



\section{ACKNOWLEDGEMENT}

It is everyone desire, as a $\mathrm{PhD}$ student, to work within a group of inspiring scientists where one enjoys and feels supportive, and I am very grateful and happy to feel that way, so I would like to take this opportunity to acknowledge a few people whom I am appreciative and thankful to;

My supervisor, Johanna Rosén, for giving me the opportunity to work within her group and for her guidance, supports, encouragement and countless discussions, and my co-supervisor, Per O. Å. Persson, for his support and advice.

My first co-supervisor, Árni Sigurður Ingason for his help in the lab, and for his enthusiasm when seeing a trace of a new 002 peak in the XRD scan $:$

Andrejs Petruhins, for his endless help and support in the lab and his patience when things got a bit out of control.

Martin Dahlqvist, for his ideas, help and comments, especially on the theoretical parts.

Joseph Halim, for being supportive and helpful and for the many hours of etching training.

Chung-Chuan Lai, for his cheerful talks and for being a great colleague and friend.

And all my colleagues and friends who supported me and made the working environment fun and joyful.

And finally, special thanks to my family, especially my husband, Ehsan, for their endless love and support. 



\section{INCLUDED PAPERS}

\section{Paper I}

Theoretical stability, thin film synthesis and transport properties of the $\mathrm{Mo}_{n+1} \mathrm{GaC}_{n} \mathrm{MAX}$ phase

Rahele Meshkian, Arni Sigurdur Ingason, Martin Dahlqvist, Andrejs Petruhins, Unnar B. Arnalds, Fridrik Magnus, Jun Lu, Johanna Rosen

Physica Status Solidi Rapid Research Letters 9, No. 3, 197-201, (2015)

I was involved in planning the project and performed all depositions, and XRD characterization, prepared TEM samples and was involved in analysis of TEM results and I wrote the paper. I also performed all theoretical simulations.

\section{Paper II}

Structural and chemical determination of the new nanolaminated carbide $\mathrm{Mo}_{2} \mathrm{Ga}_{2} \mathrm{C}$ from first principles and materials analysis

C.-C. Lai, R. Meshkian, M. Dahlqvist, J. Lu, L.-Å. Näslund, O. Rivin, E. N. Caspi, H. Ettedgui, O. Ozeri, L. Hultman, P. Eklund, M. W. Barsoum, and J. Rosen

Acta Materialia 99,157-164, (2015)

I was involved in planning the project, helped performing the depositions and XRD measurements. 


\section{Paper III}

Synthesis of two-dimensional molybdenum carbide (MXene) from the gallium based atomic laminate $\mathrm{Mo}_{2} \mathrm{Ga}_{2} \mathrm{C}$

Rahele Meshkian, Lars-Åke Näslund, Joseph Halim, Jun Lu, Michel Barsoum, Johanna Rosen

Scripta Materialia 108, 147-150, (2015)

I planned and performed the chemical etching processes, XRD characterization, prepared TEM samples and was involved in analysis of TEM results and I wrote the paper.

\section{Paper IV}

A magnetic atomic laminate from thin film synthesis; $\left(\mathrm{Moo.5}_{\mathrm{Mn}} \mathrm{Mn}_{0.5}\right)_{2} \mathrm{GaC}$

R. Meshkian, A.S. Ingason, U. B. Arnalds, F. Magnus, J. Lu and J. Rosen

APL Materials 3, 076102-5, (2015)

I was involved in planning the project and performed all material synthesis, did XRD

characterization, I prepared TEM samples and was involved in analysis of TEM and VSM results, and I wrote the paper. 


\section{Paper V}

Theoretical stability and materials synthesis of a chemically ordered MAX phase, $\mathrm{Mo}_{2} \mathrm{ScAlC}_{2}$, and its two-dimensional derivate $\mathrm{Mo}_{2} \mathrm{ScC}_{2} \mathrm{MXene}$

Rahele Meshkian, Quanzheng Tao, Martin Dahlqvist, Jun Lu, Lars Hultman, Johanna Rosen

Acta Materialia 125, 476-480 (2017)

I was involved in planning the project and performed the material synthesis, XRD characterization, Rietveld refinement and helped with the chemical etching process of the MXene, I was involved in analysis of TEM results, and I wrote the paper.

\section{Paper VI}

W-based atomic nanolaminates and their two-dimensional derivative $\mathrm{W}_{1.33} \mathrm{C}$ MXene with vacancy ordering

Rahele Meshkian, Martin Dahlqvist, Jun Lu, Björn Wickman, Joseph Halim, Jimmy Thörnberg, Quanzheng Tao, Shixuan Li, Saad Intikhab, Joshua Snyder, Michel W. Barsoum, Melike Yildizhan, Justinas Palisaitis, Lars Hultman, Per O. Å. Persson, Johanna Rosen

Advanced Materials, 1706409 (2018)

I was involved in planning the project and performed the material synthesis, XRD characterization, Rietveld refinement, I was involved in analysis of TEM results, and I wrote the paper. 



\section{LIST OF RELATED PAPERS}

\section{Magnetic properties of nanolaminated (Mo0.5Mn0.5)2 GaC MAX phase}

R. Salikhov, R. Meshkian, D. Weller, B. Zingsem, D. Spoddig, J. Lu, A. S. Ingason, H. Zhang, J. Rosen, U. Wiedwald, and M. Farle

Journal of Applied Physics 121, 163904 (2017)

Two-dimensional Mo1.33C MXene with divacancy ordering prepared from parent 3D laminate with in-plane chemical ordering

Quanzheng Tao, Martin Dahlqvist, Jun Lu, Sankalp Kota, Rahele Meshkian, Joseph Halim, Justinas Palisaitis,Lars Hultman, Michel W. Barsoum, Per O.Å. Persson \& Johanna Rosen

Nature Communications, 8, 14949 (2017)

Theoretical and experimental exploration of a novel in-plane chemically-ordered $\left(\mathrm{Cr}_{2 / 3} \mathrm{M}_{1 / 3}\right)_{2} \mathrm{AlC} i$-MAX phase with $\mathrm{M}=\mathrm{Sc}$ and $\mathrm{Y}$

Jun Lu, Andreas Thore, Rahele Meshkian, Quanzheng Tao, Lars Hultman, Johanna Rosen Crystal Growth \& Design, 17 (11), 5704-5711 (2017)

Prediction and synthesis of a family of atomic laminate phases with Kagomé-like and in-plane chemical ordering

Martin Dahlqvist, Jun Lu, Rahele Meshkian, Quanzheng Tao, Lars Hultman, Johanna Rosen

Science Advances, 3, 1700642 (2017) 



\section{Table of Contents}

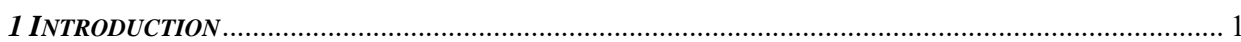

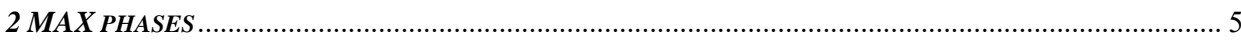

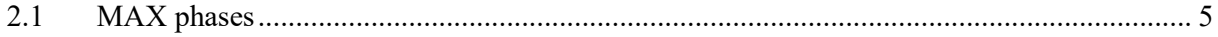

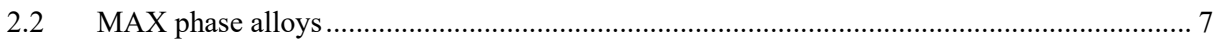

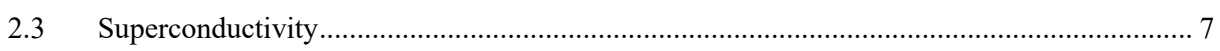

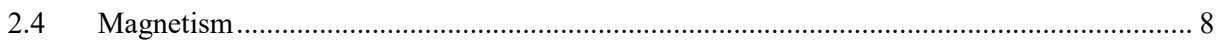

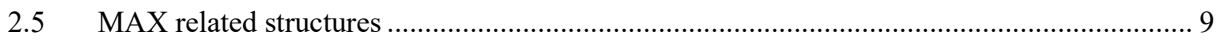

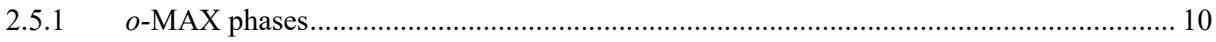

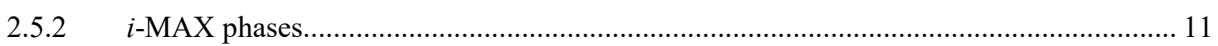

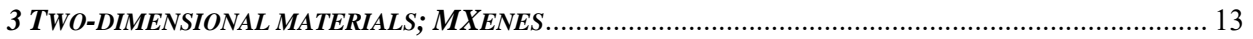

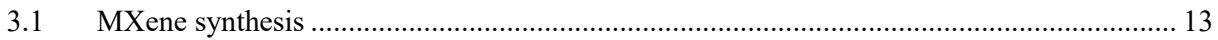

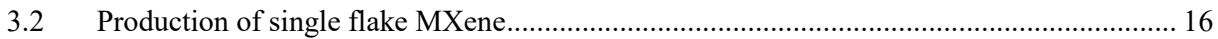

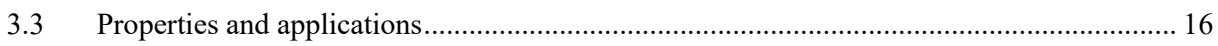

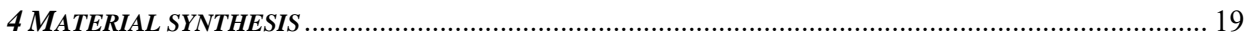

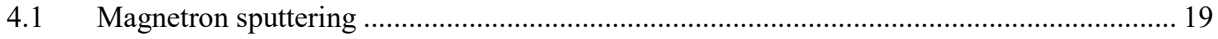

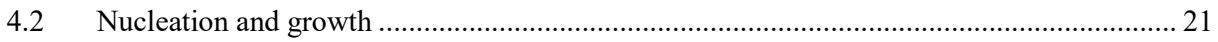

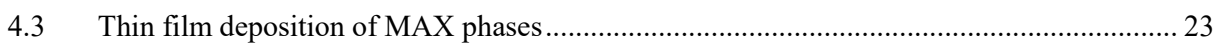

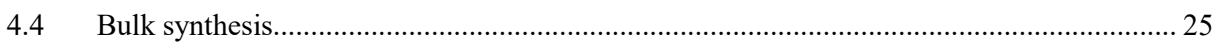

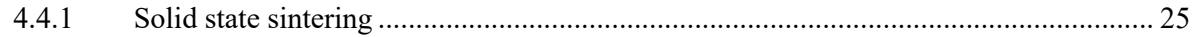

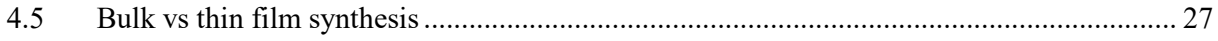

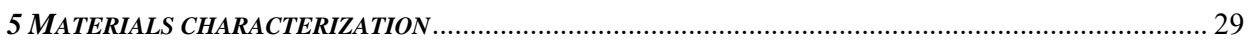

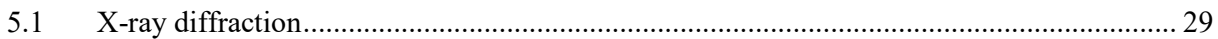

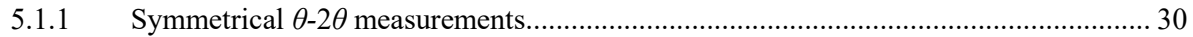

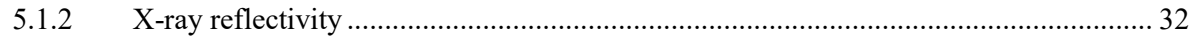

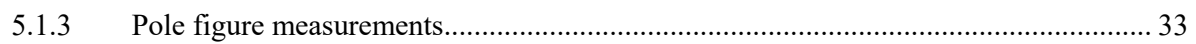

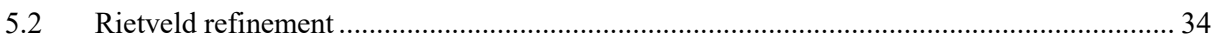

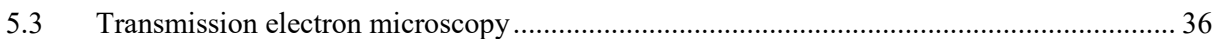

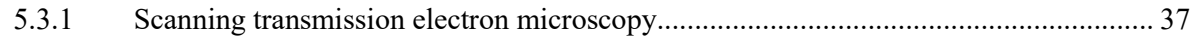

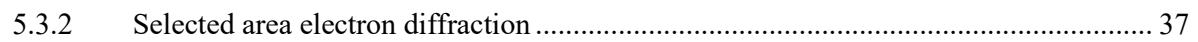

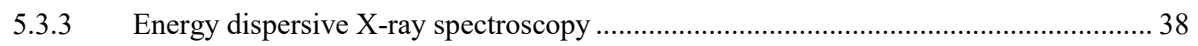

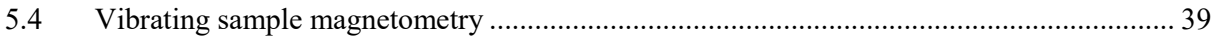

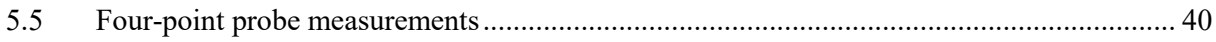

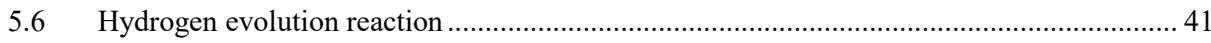

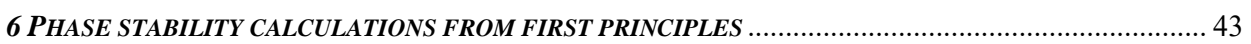

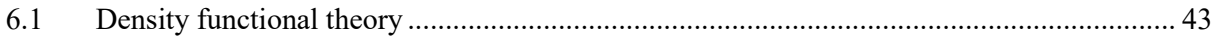




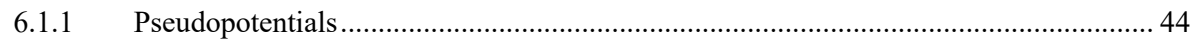

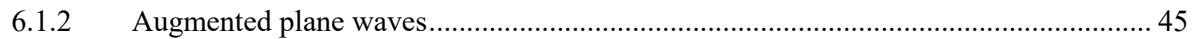

6.2 Theoretical background to phase stability calculations ........................................................ 45

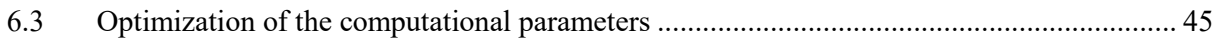

6.4 The linear optimization method used for prediction of phase stability ................................ 47

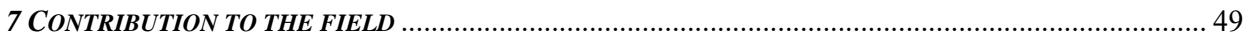

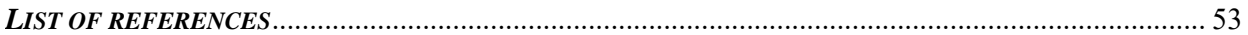




\section{INTRODUCTION}

Material science is based on detailed knowledge of materials, and how this can be employed to develop our civilization. It may be described as the correlation between synthesis, structure, properties and performance of the materials of interest. The fast development in science and technology in the last decades has increased the flexibility of material synthesis processes, which is an important tool for customizing compounds with various desired properties. Furthermore, advanced characterization and analysis of the materials composition, structure and resulting properties allows fabrication of new compounds with tailor-made properties.

As different types of materials exhibit different properties, a combination thereof may allow tuning and improvement of properties, and thus broaden the range of attainable applications. Ceramics are in general refractory, i.e., have high temperature tolerance and relatively high decomposition temperature, and are thermal shock and corrosion resistant. However, they typically have a high electrical and thermal resistivity. Hence, combining these properties with metal characteristics could allow, e.g., good electrical and thermal conductivity while also being resistant to oxidation and corrosion. This is realized in a family of inherently laminated hexagonal compounds called MAX phases, which are composed of a transition metal, $M$, an A-group element, $A$, and carbon or nitrogen, $X[1,2]$. A large number of these phases were discovered during sixties by a group in Vienna [3]. About three decades later, the interest in these compounds was re-ignited upon synthesis of $\mathrm{Ti}_{3} \mathrm{SiC}_{2}$ [4] which now is among the most studied of all MAX phases.

The areas of interest in this thesis are transport properties and magnetic properties as well as potential for hydrogen evolution reaction. Starting from superconducting materials, there are 7 MAX phases claimed to display such superconducting behavior to date, namely, $\mathrm{Nb}_{2} \mathrm{SC}$ [5], $\mathrm{Nb}_{2} \mathrm{SnC}$ [6], $\mathrm{Nb}_{2} \mathrm{AsC}$ [7], $\mathrm{Nb}_{2} \mathrm{InC}$ [8], $\mathrm{Ti}_{2} \mathrm{InC}$ [9], $\mathrm{Ti}_{2} \mathrm{InN}$ [10], and $\mathrm{Mo}_{2} \mathrm{GaC}$ [11], all synthesized in bulk form. However, it was later suggested that $\mathrm{Nb}_{2} \mathrm{SnC}$ and $\mathrm{Ti}_{2} \mathrm{InC}_{\mathrm{C}}$ do not exhibit any superconducting properties [1], and the result from Bortolozo et al. remains to be reproduced. Synthesis of such MAX phase materials in thin film form, epitaxially grown and of high crystal quality and phase purity, would be an important contribution to the field, for further characterization with respect to transport properties.

Turning to magnetism in MAX phases, it is a rather young research area, initiated by the discovery of the first magnetic MAX phase in 2013 [12]. Due to the laminated character of 
MAX phases and their very similar in-plane lattice parameters, magnetic MAX could potentially be good candidates for more advance applications requiring sharp interfaces in stacks of different materials, e.g., in hard drives in computers or for giant magneto resistance (GMR). In the latter, there is a stacking sequence of different compounds, altering between magnetic and non-magnetic layers.

Interest in clean energy has increased tremendously within the last decades, because of growing population on Earth and pollution caused by using fossil fuels. Hence, alternative sources of energy, such as solar or wind energy, have become extremely important. Hydrogen evolution reaction is a method for producing $\mathrm{H}_{2}$ for energy storage purposes, and for making this reaction more efficient, a good electrocatalyst is a necessity. However, as many of the energy storage applications benefit from a large surface are in a small volume, attention is increasingly being directed towards two-dimensional (2D) materials. Well known 2D materials are, e.g., graphene, hexagonal Boron Nitride (hBN), and transition metal dichalcogenides such as $\mathrm{MoS}_{2}$ and $\mathrm{WSe}_{2}$. In 2011, a new class of 2D materials was realized by chemical etching of the $A$-element in the parent MAX phase [13]. These 2D graphene-analogous materials were called "MXene", and they have attracted tremendous attention due to their shown high potential for a wide range of applications including energy storage devices, electrical contacts, field effect transistors, etc. However, being a comparatively young family of materials, novel compositions and new properties remains to be investigated, both from a fundamental point of view and from an application perspective.

Investigating and exploring different types of compounds in terms of structure, composition, and properties is of high interest as it potentially allows for realization of specific and tailor-made properties. Hence, the aim of my research has been to use a combination of theoretical and experimental approaches, and to synthesize and characterize novel MAX phases of high structural quality as well as their corresponding 2D derivatives, the MXenes, and to gain a deeper understanding of their properties and thus their potential applications. The research has included incorporation of new elements into traditional MAX phases and have displayed novel chemical ordering for MAX phase-based alloys, also in their 2D derivatives. Figure 1, shows a chart of the material systems I worked with during my $\mathrm{PhD}$ studies. 


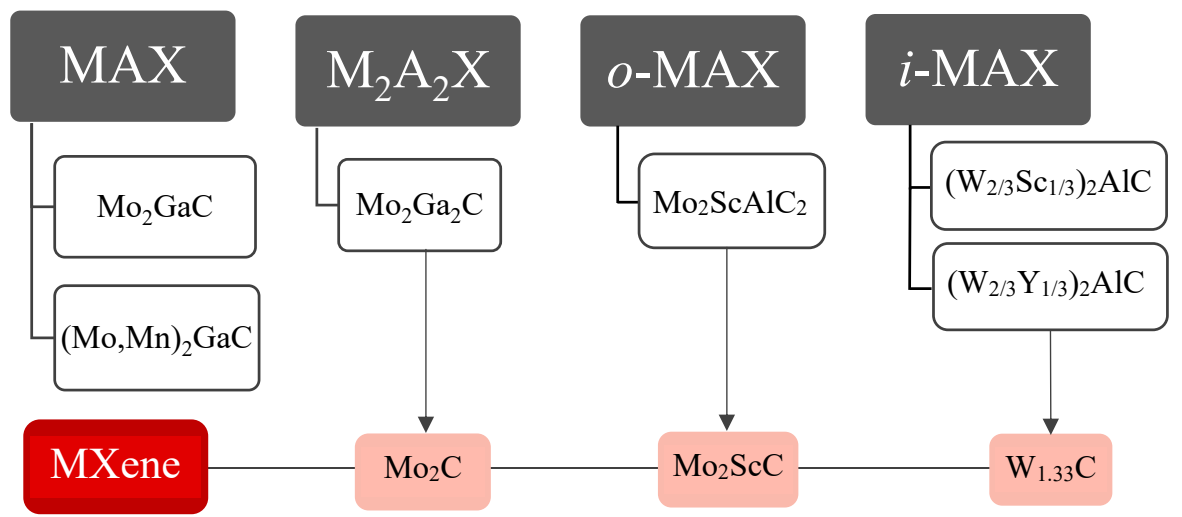

Figur 1 The schematic presents a chart of the materials systems studied in this thesis.

I initialized my studies on Mo-based phases, as these are predicted to have promising transport and thermoelectric properties in both $3 \mathrm{D}$ as well as in 2D. Motivated by theoretically predicted phase stability, $\mathrm{Mo}_{2} \mathrm{GaC}$ and a $\mathrm{MAX}$ phase-related material $\mathrm{Mo}_{2} \mathrm{Ga}_{2} \mathrm{C}$ were synthesized, allowing investigation of superconducting properties as well as realization of a new $2 \mathrm{D}$ material, $\mathrm{Mo}_{2} \mathrm{C}$. Furthermore, I substituted $50 \%$ of the Mo atoms in $\mathrm{Mo}_{2} \mathrm{GaC}$ by $\mathrm{Mn}$ atoms to induce magnetic properties, and allow exploration beyond the elemental combinations used in previously studied magnetic MAX phases.

I continued my research on synthesis and characterization of a MAX phase alloy exhibiting a chemically ordered structure in the form of out-of-plane ordering and alternating layers based on one element only, therefore called $o$-MAX. The phase was $\mathrm{Mo}_{2} \mathrm{ScAlC}_{2}$, and also its $2 \mathrm{D}$ counterpart, $\mathrm{Mo}_{2} \mathrm{ScC}$, was synthesized and characterized. The first such phase was discovered 2014 by Liu et al. [14], where he synthesized and characterized $\mathrm{Cr}_{2} \mathrm{TiAlC}_{2}$ and $\left(\mathrm{Cr}_{5 / 8} \mathrm{Ti}_{3 / 8}\right)_{4} \mathrm{AlC}_{2}$. In 2017, Tao et al. [15], discovered a new type of chemically ordered MAX phase alloy, $\left(\mathrm{Mo}_{2 / 3} \mathrm{Sc}_{1 / 3}\right)_{2} \mathrm{AlC}$, which is in-plane chemically ordered in the M-layer, and therefore coined $i$-MAX. Most importantly, its 2D counterpart is a MXene with ordered vacancies, $\mathrm{Mo}_{1.33} \mathrm{C}$. That is due to the removal of the Sc atoms in addition to the Al-layers in the etching process. Apart from a high conductivity, the vacancy-MXene showed a high potential as electrode materials in energy storage applications. 
My final project realized incorporation of a new element, $\mathrm{W}$, into an $i$-MAX phase, motived by a theoretically predicted excellent catalytic behavior for hydrogen evolution reaction (HER) as well as a predicted potential for being a topological insulator for the hypothetical $\mathrm{W}_{2} \mathrm{C}$ MXene [16]. Inspired by theoretical predictions, I discovered the $i$-MAX phases $\left(\mathrm{W}_{2 / 3} M^{2}{ }_{1 / 3}\right)_{2} \mathrm{AlC}$, where $M^{2}=\mathrm{Sc}$ and $\mathrm{Y}$, and their corresponding MXenes with ordered vacancies, $\mathrm{W}_{1.33} \mathrm{C}$. The latter were synthesized and characterized with respect to structure, composition, and HER. Altogether, the results showed a high potential for HER, which is the topic of future studies. 


\section{MAX PHASES}

Hans Nowotny and his coworkers discovered a large family of carbides and nitrides, $~ 100$ phases, in the 1960s in Vienna [3]. Amongst these, there were 39 phases, called "H-phases" or $\mathrm{Cr}_{2} \mathrm{AlC}$-type phases. However, they were not fully explored until the 1990s, when Barsoum and his group revived this family of material which was then given the nomenclature of "MAX-phases" [17].

\subsection{MAX phases}

$M_{n+1} A X_{n}$ phases (MAX), with $n=1,2,3, \ldots$, are a family of inherently (thermodynamically stable) nanolaminated compounds, crystallizing in hexagonal structure within the space group $P 6_{3} / m m c$ (194). These are composed of transition metals (M), A-group elements, primarily group $13-16(A)$ and carbon or nitrogen $(X)[1]$, shown in Table I.

Table I. The highlighted elements are the constituents of the known MAX phases, red, blue and gray colors denote the transition metals $(M)$, A-group elements $(A)$ and carbon or nitrogen $(X)$.

\begin{tabular}{|c|c|c|c|c|c|c|c|c|c|c|c|c|c|c|c|c|c|}
\hline $\mathrm{H}$ & & & & & & & & & & & & & & & & & $\mathrm{He}$ \\
\hline $\mathrm{Li}$ & $\mathrm{Be}$ & & & & & & & & & & & B & $\mathrm{C}$ & $\mathrm{N}$ & $\mathrm{O}$ & $F$ & $\mathrm{Ne}$ \\
\hline $\mathrm{Na}$ & $\mathrm{Mg}$ & & & & & & & & & & & $\mathrm{Al}$ & $\mathrm{Si}$ & $\mathrm{P}$ & $\mathrm{S}$ & $\mathrm{Cl}$ & $\mathrm{Ar}$ \\
\hline $\mathrm{K}$ & $\mathrm{Ca}$ & $\overline{S c}$ & $\overline{\mathrm{Ti}}$ & $\mathrm{V}$ & $\overline{\mathrm{Cr}_{\mathrm{r}}}$ & $\overline{M r}$ & $\mathrm{Fe}$ & $\mathrm{Co}$ & $\mathrm{Ni}$ & $\mathrm{Cu}$ & $\mathrm{Zn}$ & $\mathrm{Ga}$ & $\mathrm{Ge}$ & As & $\mathrm{Se}$ & $\mathrm{Br}$ & $\mathrm{Kr}$ \\
\hline $\mathrm{Rb}$ & $\mathrm{Sr}$ & $\mathrm{Y}$ & $\mathrm{Zr}$ & $\mathrm{Nb}$ & Mo & $\mathrm{Tc}$ & $\mathrm{Ru}$ & $\mathrm{Rh}$ & $\mathrm{Pd}$ & $\mathrm{Ag}$ & $\mathrm{Cd}$ & In & $\mathrm{Sn}$ & $\mathrm{Sb}$ & $\mathrm{Te}$ & I & $\mathrm{Xe}$ \\
\hline $\mathrm{Cs}$ & $\mathrm{Ba}$ & $\overline{\mathrm{Lu}}$ & $\mathrm{Hf}$ & $\mathrm{Ta}$ & W & $\mathrm{Re}$ & Os & Ir & $\overline{\mathrm{Pt}}$ & $\mathrm{Au}$ & $\mathrm{Hg}$ & $\mathrm{T1}$ & $\mathrm{Pb}$ & $\mathrm{Bi}$ & Po & At & $R_{n}$ \\
\hline $\mathrm{Fr}$ & $\mathrm{Ra}$ & $\mathrm{Lr}$ & $\mathrm{Rf}$ & $\mathrm{Db}$ & $\mathrm{Sg}$ & $\mathrm{Bh}$ & Hs & $\mathrm{Mt}$ & Ds & $\mathrm{Rg}$ & $\mathrm{Cn}$ & Uut & $\mathrm{F} 1$ & Uup & $\mathrm{Lv}$ & Uns & Uno \\
\hline
\end{tabular}

In these materials, the $A$-element is located at the center of a trigonal prism, sandwiched between the octahedral $M X$ site. MAX phases can mainly be synthesized in three stoichiometries $(n=1-3)$, which are often referred to as 211,312 and 413 . The difference between these three configurations is the number of $M_{n+1} X_{n}$ layers separating the $A$-layer. The in-plane lattice parameter, $a$, in all three stoichiometries is similar, $\sim 3 \AA$. However, the out-ofplane lattice parameter, $c$, increases going from 211 to 413 structure, i.e., $c \sim 13, \sim 18$ and $24 \AA$ for 211,312 and 413, respectively [18]. 
The interest in these compounds stem from the fact that they display a unique combination of metallic and ceramic properties, which is due to their layered structure and that there is a mixture of metallic, covalent, and ionic bonding between the individual elements within these materials [19]. For instance, MAX phases exhibit high electrical and thermal conductivity, oxidation and thermal shock resistance. They are quiet stiff, light-weight, and easily machinable. They accommodate deformation by forming shear and kink bands [20]. To date, more than 70 MAX phases have been synthesized in both bulk and thin film form. Figure 2, illustrates the atomic stacking of these compounds along the $c$-axis.

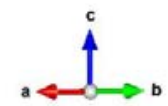

$\mathrm{M} \bullet \mathrm{A} \cdot \mathrm{C}$

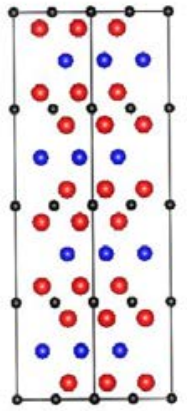

211

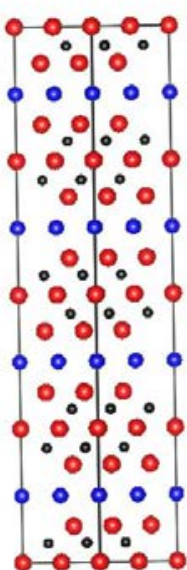

312

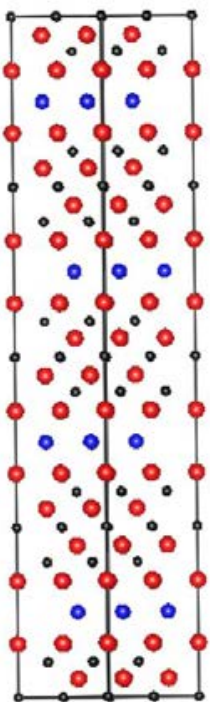

413

Figure 2 Schematic illustration of the atomic sequence of 211, 312 and 413 MAX phases along c-direction.

Related intergrown structures, e.g., 523 and 725 have also been reported by e.g., Palmqvist et al. $[18,21]$ in the Ti-Si-C system.

Further, the optimal growth temperature of the MAX phase compounds vary in a wide range, e.g., $\sim 450^{\circ} \mathrm{C}$ for $\mathrm{Cr}_{2} \mathrm{AlC}$ [22] and $\mathrm{V}_{2} \mathrm{GeC}$ [23], whereas $\mathrm{Ti}_{2} \mathrm{AlC}$ requires a temperature slightly higher than $900^{\circ} \mathrm{C}$ to nucleate. The lowest $\left(\sim 850^{\circ} \mathrm{C}\right)$ and the highest $\left(\sim 2300^{\circ} \mathrm{C}\right)$ decomposition temperatures reported to date are observed for $\mathrm{Cr}_{2} \mathrm{GaN}$ [18] and $\mathrm{Ti}_{3} \mathrm{SiC}_{2}[24,25] \mathrm{MAX}$ phases, respectively. It should be mentioned that MAX phases normally decompose through interplanar diffusion of the $A$-layer. 


\subsection{MAX phase alloys}

The possibility to combine different elements at the M, A and X site of MAX phases and form an alloy is motivated by the possibility to improve and/or tune for example, the electrical, mechanical and in some cases, magnetic properties of these materials. The alloying is possible in either $M$-, $A$ - or $X$-site where the best candidates, for obtaining a solid solution, are the neighboring atoms, which are similar in size and electronic configuration, e.g. ( $\mathrm{Ti}, \mathrm{Nb})_{2} \mathrm{AlC}$ [26], $\mathrm{Ti}_{3}\left(\mathrm{Si}_{0.43} \mathrm{Ge}_{0.57}\right) \mathrm{C}_{2}$ [27], $\mathrm{Ti}_{3}\left(\mathrm{Al}, \mathrm{Sn}_{0.2}\right) \mathrm{C}_{2} \quad$ [28], $\left(\mathrm{Ti}_{0.5}, \mathrm{~V}_{0.5}\right)_{3} \mathrm{AlC}_{2}, \quad\left(\mathrm{Nb}_{0.5}, \mathrm{~V}_{0.5}\right)_{2} \mathrm{AlC}$, $\left(\mathrm{Nb}_{0.5}, \mathrm{~V}_{0.5}\right)_{4} \mathrm{AlC}_{3}$ and $\left(\mathrm{Nb}_{0.5}, \mathrm{Zr}_{0.5}\right)_{2} \mathrm{AlC}$ [29]. In one study, substitution of $20 \%$ of $\mathrm{Ti}$ atoms by vanadium (V) increased the Vickers hardness substantially in the $\mathrm{Ti}_{2} \mathrm{AlC}$ phase [30].

Further, theoretical calculations as well as experimental investigation on the incorporation of oxygen in $\mathrm{Ti}_{2} \mathrm{AlC}$ on the $X$-site have suggested anisotropic electrical behavior in the $a$ - and $c$-directions as well as that the electrical conductivity may alter from an insulating to a conducting response [31,32]. Another example of $X$-site solid solutions [33] is where $\mathrm{Ti}_{2} \mathrm{AlC}$ is alloyed with nitrogen, forming, $\mathrm{Ti}_{2} \mathrm{AlC}_{0.5} \mathrm{~N}_{0.5}$, resulting in a much harder and stiffer compound than either of the end members.

Moreover, replacing a fraction of the $M$ atoms with manganese $(\mathrm{Mn})$ in $\left(\mathrm{Cr}_{0.5} \mathrm{Mnn}_{0.5}\right)_{2} \mathrm{GaC}$ [34], $\left(\mathrm{Cr}_{0.75} \mathrm{Mn}_{0.25}\right)_{2} \mathrm{GeC}$ [12], and ( $\left.\mathrm{Cr}, \mathrm{Mn}\right)_{2} \mathrm{AlC}$ [35] MAX phases, have induced magnetic behavior in these compounds. In paper IV, we present that incorporation of $50 \% \mathrm{Mn}$ atoms in the $M$-site in $\mathrm{Mo}_{2} \mathrm{GaC}$ MAX phase, resulted in an enhanced magnetic response, from non-magnetic to a degenerate state of ferro/antiferromagnetic (FM/AFM) behavior.

\subsection{Superconductivity}

Superconductors were discovered in 1911, when the Dutch physicist Heike Kamerlingh Onnes measured the resistivity of mercury at liquid helium temperature and observed that the resistivity suddenly dropped at a temperature of $\sim 4 \mathrm{~K}$ [36]. Henceforth, discovering superconducting materials with high transition temperatures has always been an important area of research, implying a wide range of applications [37, 38], such as low loss power cables, nuclear magnetic resonance machines and particle detectors, just to mention a few.

The first MAX phase indicating possible superconducting behavior, $\mathrm{Mo}_{2} \mathrm{GaC}$, was synthesized in bulk form by L.E. Toth [11], in 1967. Later, a number of other MAX compounds were claimed to be superconductive, e.g., $\mathrm{Nb}_{2} \mathrm{SC}$ [5], $\mathrm{Nb}_{2} \mathrm{SnC}$ [6], $\mathrm{Nb}_{2} \mathrm{AsC}$ [7], $\mathrm{Ti}_{2} \mathrm{InC}$ [9], 
$\mathrm{Nb}_{2} \operatorname{InC}[8]$, and $\mathrm{Ti}_{2} \operatorname{InN}[10]$. However, some of these materials remain to be reproduced and the claims remain to be confirmed by other groups [1].

Nevertheless, the previously reported indications encouraged the work presented in paper I, where theoretical calculations confirmed the existence of the 211-stoichiometric phase within Mo-Ga-C system, with subsequent material synthesis of the corresponding phase in thin film form. As the crystal quality and impurity phases in the sample, has a huge impact on transport properties, the aim was to synthesize $\mathrm{Mo}_{2} \mathrm{GaC}$ phase in thin film form to obtain a highly oriented sample with less grain boundaries and impurities which are known common artefacts in bulk synthesis.

\subsection{Magnetism}

Magnetic materials have been used in compasses for centuries. The first magnetic material known was Lodestone, or leading stones, which are naturally magnetic pieces. A search for new magnetic compounds, and investigations of these materials, has been an elevated research topic in recent years, especially layered magnetic materials as such systems have a large potential for applications in e.g., hard drives, magnetic resonance imaging equipment, magnetoresistors [39] and spintronics [40].

3D transition metals, normally with an unpaired electron, have a positive net magnetic moment. Among these elements, Fe, Co and Ni show FM behavior with a Curie temperature well above room temperature.

The first study on hypothetical magnetic MAX phases was a theoretical investigation reported by W. Luo and R. Ahuja [41], exploring the stability and magnetic behavior of $\mathrm{Fe}_{n+1} A \mathrm{C}_{n}$ where, $A=\mathrm{Al}, \mathrm{Si}$ and Ge. In this work, $\mathrm{Fe}_{3} \mathrm{AlC}_{2}$ was suggested to display a $\mathrm{FM}$ behavior with a magnetic moment of about $0.73 \mu_{\mathrm{B}}$ per Fe atom. However, this remains to be experimentally confirmed. Another theoretical investigation performed by Dahlqvist et al. [42] predicted a stable magnetic MAX phase, $\left(\mathrm{Cr}_{1-x} \mathrm{Mn}_{x}\right)_{2} \mathrm{AlC}$, with $x<0.5$. Inspired by this theoretical study, Mockuté et al. [43] succeeded to synthesize this phase and subsequent characterization of the magnetic properties showed a FM/AFM response up to at least $280 \mathrm{~K}$.

Alloying different MAX phases with a magnetic element could consequently induce magnetism and allow for tuning or altering the magnetic response of the material. For instance, substitution of a fraction of the $M$-element with manganese (Mn) in resulting $\left(\mathrm{Cr}_{0.5} \mathrm{Mn}_{0.5}\right)_{2} \mathrm{GaC}$ [34], $\left(\mathrm{Cr}_{0.75} \mathrm{Mn}_{0.25}\right)_{2} \mathrm{GeC}[12]$, and $\left(\mathrm{Cr}_{1-x} \mathrm{Mn}_{x}\right)_{2} \mathrm{AlC}$ [43-45] has been a successful approach for 
introducing magnetism into these phases. The exchange interaction between the $\mathrm{Mn}$ atoms and the other $M$-element of these MAX phases results in a change in the net magnetization and, in turn, a change in the magnetic behavior of the compounds.

Further studies of magnetic MAX phases include, e.g., a work performed by Liu et al. [46] regarding $\mathrm{Cr}_{2} \mathrm{GeC}$ alloyed with different $\mathrm{Mn}$-concentration. The study suggests that the obtained magnetic response of this phase could be explained by itinerant magnetism, as opposed of having a local magnetic moment. However, further analysis is required to really confirm this statement.

Furthermore, an important contribution to the field was the discovery of $\mathrm{Mn}_{2} \mathrm{GaC}$ [47], the first MAX phase including $\mathrm{Mn}$ as a sole $M$-element, which, at $\mathrm{T}_{\mathrm{t}}=214 \mathrm{~K}$, undergoes a transition from AFM to a non-collinear AFM spin structure [48].

Regardless the magnetic response obtained in $\mathrm{Cr} / \mathrm{Mn}$ based magnetic MAX phases to date, discovering a ferromagnetic material with high remanence and coercive field (around room temperature) would be highly desired for future potential applications such as magnetic storage devices. Therefore, realization of Mo-based MAX phases and exploration of the magnetic response was the aim of paper IV. In that study, after replacing $50 \%$ of Mo atoms within the films with Mn atoms, the magnetic behavior of the thin films was measured using a vibrating sample magnetometer, indicating a non-collinear (non-parallel) spin configuration with a $\mathrm{FM} / \mathrm{AFM}$ response up to at least $150 \mathrm{~K}$.

\subsection{MAX related structures}

As mentioned previously, alloying of MAX phases can allow improvement and tuning of various properties. Recently, alloying has also led to the discovery of chemically ordered structures. This, in turn, provide the possibility of incorporating new elements, not included in traditional MAX phases, e.g., Sc, and $\mathrm{W}$, and $\mathrm{Y}$, in $\mathrm{Mo}_{2} \mathrm{ScAlC}_{2},\left(\mathrm{~W}_{2 / 3} \mathrm{Sc}_{1 / 3}\right)_{2} \mathrm{AlC}$, and $\left(\mathrm{W}_{2 / 3} \mathrm{Y}_{1 / 3}\right)_{2} \mathrm{AlC}$, respectively. In the last few years, theoretical and experimental studies on alloyed MAX phases have led to the discovery of two new MAX-related groups of solids; out-of-plane and in-plane chemically ordered MAX phases, which are denoted as " $o$-MAX" and " $i$-MAX", respectively. In the following, a brief description of these compounds will be provided. 


\subsection{1 o-MAX phases}

The first out-of-plane chemically order MAX phase was $\mathrm{Cr}_{2} \mathrm{TiAlC}_{2}$, reported by Liu et al. [14] in 2014. Analysis of the data showed that $\mathrm{Cr}$ and $\mathrm{Ti}$ atoms are positioned in $4 \mathrm{f}$ and $2 \mathrm{a}$ Wyckoff positions, respectively. The difference between this new structure and the traditional $M$-site alloyed MAX phase structure is that, in the former, the $M$-elements tend to arrange themselves in an ordered manner in the $c$ direction, where each individual layer consists of solely one type of atom. Hence, the notation can also be formulated as $M_{2}^{1} M^{2} A C_{2}$ or $M_{2}^{1} M_{2}^{2} A C_{3}$.

Shortly after the first discovery, other combinations of elements with similar chemical ordering, were reported; $\mathrm{V}_{1.5} \mathrm{Cr}_{1.5} \mathrm{AlC}_{2}$ [49], $\mathrm{Mo}_{2} \mathrm{TiAlC}_{2}$ and $\mathrm{Mo}_{2} \mathrm{Ti}_{2} \mathrm{AlC}_{3}$ [50]. However, in the case of the $\mathrm{V}_{1.5} \mathrm{Cr}_{1.5} \mathrm{AlC}_{2}$ phase, a solid solution in the $M$-site was also observed, meaning that not a complete chemical order was obtained. As the traditional MAX phase, these compounds also crystallize in hexagonal structure within the space group $194\left(\mathrm{P}_{3} / \mathrm{mmc}\right)$. The reason behind this chemical order can be explained by the difference between the two $M$-elements atomic radii and their different electronegativity. Thus, not all combination of $M$-elements will result in a chemically ordered structure. Further, this ordering is possible for stoichiometries with $n \geq 2$, due to that there are more than one crystallographic $M$-site in these structures, providing a higher structural stability upon alloying in these compounds.

As suggested by Dahlqvist et al. [51], in the case of the $\mathrm{Mo}_{2} \mathrm{TiAlC}_{2}$ phase, the origin of the ordering is likely due to the fact that Ti breaks an unfavorable stacking of the Mo atoms which are surrounded by the $\mathrm{C}$ atoms in a face centered cubic arrangement. And, since Mo has a higher electronegativity (2.16) than that of $\mathrm{Ti}$ (1.54), when Mo is closer to the Al layers, fewer electrons would populate the antibonding Al-Al orbitals, which is energetically unfavorable.

Chemical ordering is also realized in paper $\mathrm{V}$, where a combination of Mo and Sc form a new $o$-MAX phase, $\mathrm{Mo}_{2} \mathrm{ScAlC}_{2}$. This is the first time a Sc-containing MAX phase and its 2D derivative, MXene, have been synthesized and characterized. It is worth to mention that there is a previous report, mentioning the existence of $\mathrm{Sc}_{2} \mathrm{InC}$ MAX phase [52], however, there is to our knowledge no information regarding synthesis and characterization of this phase. In the case of $\mathrm{Mo}_{2} \mathrm{ScAlC}_{2}$, it is not energetically favorable for either Mo or Sc atoms to be surrounded by $\mathrm{C}$ atoms in a fcc configuration, which means, the unfavorable stacking cannot be broken by Sc atoms, like for the case of Ti. Hence, the stability of $\mathrm{Mo}_{2} \mathrm{ScAlC}_{2} \mathrm{MAX}$ phase is possibly influenced by the large difference in electronegativity between Sc (1.36) and Mo (2.16). Figure 3 shows the stacking of the $\mathrm{Mo}_{2} \mathrm{ScAlC}_{2}$ phase, in the $c$ direction. 


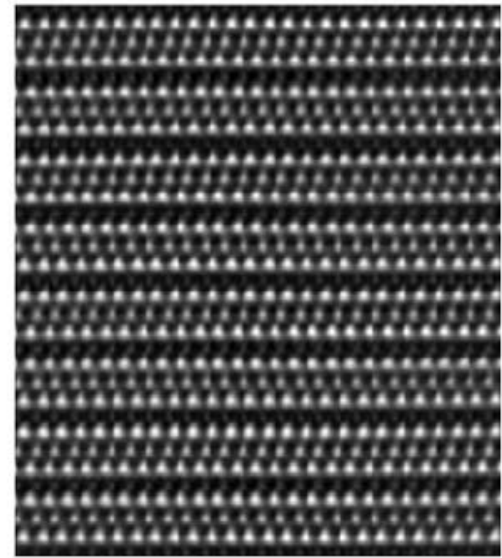

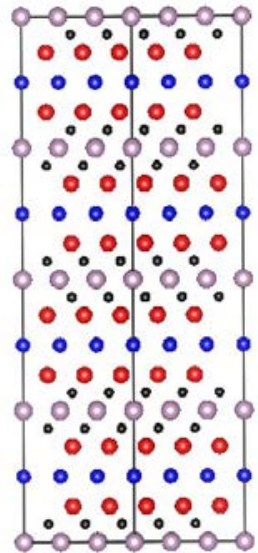

O $\mathrm{Sc}$ Mo $\mathrm{Al} \cdot \mathrm{C}$

Figure 3 A STEM image showing the structure of $\mathrm{Mo}_{2} \mathrm{ScAlC}_{2}$ phase, and its schematic illustration of the ordered laminated structure of that $o$-MAX phase.

\subsection{2 i-MAX phases}

For $i$-MAX phases, with the notation; $\left(M_{2 / 3}^{1} M_{1 / 3}^{2}\right)_{2} A C$, the hexagonal structure of the material is altered due to the tendency of the $M$-elements to be arranged in an ordered manner within the $M$ plane. In this case, the material crystallizes into the monoclinic structure, within the space group $15(\mathrm{C} 2 / \mathrm{c})$. However, crystallization in other structures has also been observed, e.g., an orthorhombic structure, of the space group $63(\mathrm{Cmcm})$.

The first $i$-MAX discovered, $\left(\mathrm{Mo}_{2 / 3} \mathrm{Sc}_{1 / 3}\right)_{2} \mathrm{AlC}$, was reported by Tao et al. [15], in 2017. This was afterwards followed by another study, performed by Dahlqvist et al. [53], suggesting that these two crystal structures (space groups) are degenerate in energy and thus a combination of both structures within the same sample is not surprising, such as in $\left(\mathrm{Cr}_{2 / 3} \mathrm{Sc}_{1 / 3}\right)_{2} \mathrm{AlC}$ [54].

The discovery of $i$-MAX phases led to expansion of the MAX phase family and incorporation of several new $M$-elements which had never been utilized in traditional MAX phases. Among such elements are rare earth metals, which, because of their unfilled $4 \mathrm{f}$ atomic shells have interesting magnetic properties. Hence, $i$-MAX compounds allow for further investigation and exploration of specifically magnetic properties. 
In paper VI, I report the discovery of two new $i$-MAX phases, $\left(\mathrm{W}_{2 / 3} \mathrm{Sc}_{1 / 3}\right)_{2} \mathrm{AlC}$ and $\left(\mathrm{W}_{2 / 3} \mathrm{Y}_{1 / 3}\right)_{2} \mathrm{AlC}$, incorporating $\mathrm{W}$ as the $M$-element for the first time. Figure 4 shows the atomic arrangements of the $\mathrm{C} 2 / \mathrm{c}$ structure in $\left(\mathrm{W}_{2 / 3} \mathrm{Sc}_{1 / 3}\right)_{2} \mathrm{AlC}$ from three different zone axes.
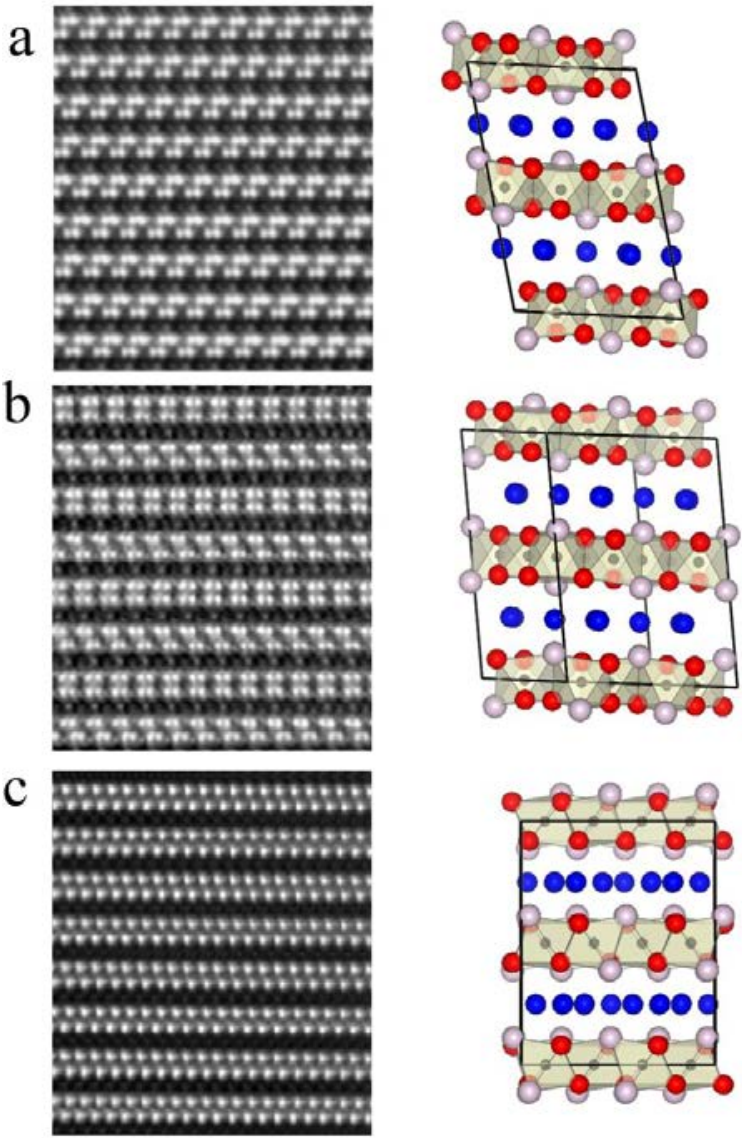

O $\mathrm{Sc}$-W $\bullet \mathrm{Al} \cdot \mathrm{C}$

Figure 4 STEM images and schematic illustration of the crystal structure of $\left(\mathrm{W}_{2 / 3} \mathrm{Sc}_{1 / 3}\right)_{2} \mathrm{AlC}$, which is an $i$-MAX phase belonging to the space group $\mathrm{C} 2 / \mathrm{c}(15)$. The micrographs are obtained along the a) [010], b) [110] and c) [100] zone axis. 


\section{TWO-DIMENSIONAL MATERIALS; MXENES}

Graphene is one the most explored 2D material to date. It is composed of a single or a few sheets of hexagonal lattice $\mathrm{sp}^{2}$ carbon with covalent bonds between the atoms within the planes, while the sheets are bonded together via weak Van der Waals forces. With its high electrical conductions properties, it has gained much attention in various field, e.g., as electrodes in Li-ion batteries [55-58], supercapacitors [59-62], electrical contact [63], etc.

Another class of 2D compounds is the layered transition metal dichalcogenides, with the formula $M X_{2}$, where $M$ is a transition metal, normally from group IV to VI, and $X$ is a chalcogen element, e.g., $\mathrm{S}$ and $\mathrm{Se}$, for example forming $\mathrm{MoS}_{2}, \mathrm{NbSe}_{2}$ and $\mathrm{WSe}_{2}$. These materials also exhibit an excellent electrical and thermal conductivity. They can be used as transistors, for energy storage and in optoelectronic devices [64-67].

Recently, a new family of graphene-analogous materials, MXenes, was discovered, exhibiting a high electrical conductivity whereas, at the same time, being hydrophilic [68]. $\mathrm{Ti}_{2} \mathrm{C}[56,69]$, $\mathrm{Ti}_{3} \mathrm{C}_{2}[68,70], \mathrm{Ta}_{4} \mathrm{C}_{3}, \mathrm{TiNbC},\left(\mathrm{V}_{0.5} \mathrm{Cr}_{0.5}\right)_{3} \mathrm{C}_{2}, \mathrm{Ti}_{3} \mathrm{CN}_{x}(x<1)$ [69], $\mathrm{V}_{2} \mathrm{C}$ and $\mathrm{Nb}_{2} \mathrm{C}$ [57] $\mathrm{Mo}_{2} \mathrm{C}$ [59, 71], $\mathrm{Mo}_{2} \mathrm{TiC}, \mathrm{Mo}_{2} \mathrm{Ti}_{2} \mathrm{C}$ [72] and $\mathrm{Mo}_{1.33} \mathrm{C}$ [15] are a number of MXene compounds synthesized to date. It is also worth to mention that $\mathrm{Mo}_{1.33} \mathrm{C}$ is among a most recently discovered family of MXenes, forming ordered divacancies.

\subsection{MXene synthesis}

MXenes are produced through exfoliation of the laminated MAX phases upon selective etching of the $A$-layers by immersing the compounds into a suitable acid solution (etchant). Removal of the $A$-element is possible due to a weaker bond between the $M-A$ layers compared to the stronger combination of metallic, ionic and covalent bonds between the $M-X$ layers. Hence, the $A$-layers in MAX phases are more prone to the chemical reactions than the MX-layers. After the etching process, the $c$ lattice parameter of the remaining material will expand due to intercalation of water molecules and other reaction residuals within the layers. The most frequently chemicals utilized for etching are hydrofluoric acid (HF) or a mixture of lithium fluoride $(\mathrm{LiF})$ and hydrochloric acid $(\mathrm{HCl})$. Figure 5 illustrates the conversion of a $211 \mathrm{MAX}$ phase to the MXene upon the etching treatment. 

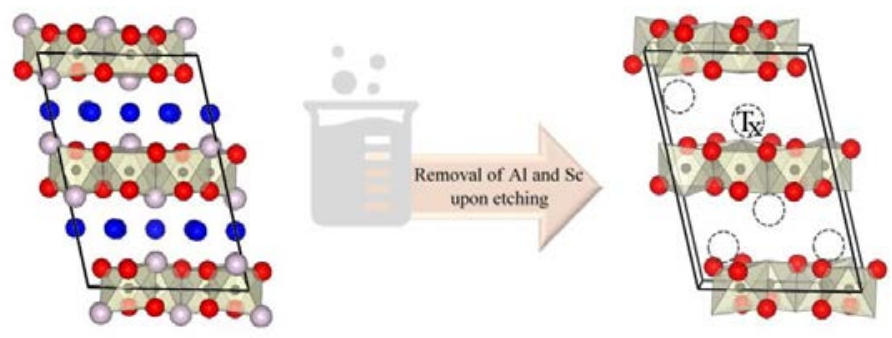

Figure 5 Formation of MXene after etching the parent $i$-MAX phase. The $\mathrm{Al}$ (and in this case Sc) layers are removed. $\mathrm{T}_{\mathrm{x}}$ denotes the surface functionalization groups which are the rest products of the etching treatments.

Using different etchant will lead to different types of intercalation and surface termination elements and/or compounds, e.g., $-\mathrm{OH},-\mathrm{O}$, -F, thus the correct formula for MXenes would include these functional groups, $M_{n+1} X_{n}(\mathrm{OH})_{\mathrm{x}} \mathrm{O}_{\mathrm{y}} \mathrm{F}_{\mathrm{z}}$, abbreviated generally as $\mathrm{T}_{\mathrm{x}} ; M_{n+1} X_{n} \mathrm{~T}_{\mathrm{x}}$ [73], shown in figure 5. According to several theoretical calculations the most energetically favorable sites for accommodation of these termination groups would be directly above $\mathrm{M}$ and $\mathrm{X}$ atoms $[55,74-77]$. Further, there are theoretical studies on how these functionalized groups impact the properties of the terminated MXenes, for example as in a study reported by M. Khazaei et al. [78] where he theoretically calculates the effect of different $T_{x}$ on electronic behavior of $\mathrm{Sc}_{2} \mathrm{C}, \mathrm{Ti}_{2} \mathrm{C}, \mathrm{Zr}_{2} \mathrm{C}$, and $\mathrm{Hf}_{2} \mathrm{C}$ MXenes, suggesting semiconductor-like behavior for these phases upon certain functionalizations, and on magnetic behavior, where terminated $\mathrm{Cr}_{2} \mathrm{C}$ and $\mathrm{Cr}_{2} \mathrm{~N}$ phases are suggested to display magnetic response, i.e., to form magnetic 2D materials, which has been a long-standing quest in the field of 2D materials. Another theoretical and experimental study performed by Xie et al. [79], suggests that the $-\mathrm{O}$ terminated $\mathrm{Sc}_{2} \mathrm{C}, \mathrm{Ti}_{2} \mathrm{C}$, $\mathrm{Ti}_{3} \mathrm{C}_{2}, \mathrm{~V}_{2} \mathrm{C}, \mathrm{Cr}_{2} \mathrm{C}$, and $\mathrm{Nb}_{2} \mathrm{C}$, have higher Li-ion storage capacity.

The morphology of the parent MAX phases and choice of synthesis approach influence the quality of and behavior of MXenes. For example, for a single crystal phase, the diffusion of the etchant will only take place from the edges and the sides of the sample, making the etching less efficient, and thus prolonging the process time. For a polycrystalline sample, on the other hand, with grain boundaries and defects such as voids and stacking faults, diffusion of the etchant is easier and faster.

The thickness of a film or size of a grain in a bulk material, also affects the diffusivity of the acid into the material, i.e., for a thicker sample, where the number of layers is higher, the film 
is chemically more stable and hence it will take longer for the etchant to fully react with the $A$-layers.

Using different etchant will also lead to obtaining different quality MXenes. MXenes treated with milder etchant such as $\mathrm{LiF}-\mathrm{HCl}$ will typically have larger flake size and contain lower concentration of defects within the sample [59, 80, 81]. When exposed to air, MXenes will usually get oxidized very fast and thus their surface terminations ratios will change by time [79].

The impact of different $A$-elements on the etching process and the quality of the produced MXene is the topic for a theoretical study investigating the influence of different $A$-layers on the exfoliation energy for different $\mathrm{Mo}_{2} A \mathrm{C}$ phases, where $A=\mathrm{Al}, \mathrm{Si}, \mathrm{P}, \mathrm{Ga}, \mathrm{Ge}, \mathrm{As}$ or In [82]. In this paper, the authors have claimed that the lowest and the highest exfoliation energies belong to $\mathrm{Mo}_{2} \mathrm{InC}(\sim-3.544 \mathrm{eV})$ and $\mathrm{Mo}_{2} \mathrm{AsC}(\sim-2.818 \mathrm{eV})$, respectively. To date, excluding the work presented in this thesis, only $A=\mathrm{Al}$ has realized a MXene. However, the results imply that other $A$-elements may be of interest for MXene synthesis.

The $M$-elements composing the MAX phase also affect the choice of etchant and the etching conditions. The heavier they are, such as $\mathrm{Mo}, \mathrm{Ta}, \mathrm{Nb}$ and $\mathrm{V}$, the stronger etchant and longer etching time is required, which might be due to stronger M-A bonds in these systems [83, 84]. Synthesis of MXene samples from the newly discovered $i$-MAX compounds has opened many new potential applications for these materials, as the Sc- or Y-containing $i$-MAX phases can form ordered vacancies in the derived MXenes due to the partial removal of the $M$-layers, along with the $A$-layers. A schematic illustration of the conversion of an $i$-MAX phase to its MXene counterpart, after the etching process, is shown in Figure 6.

In paper III, MXene formation involving novel $M$ - and $A$-elements are studied. Here, we, for the first time, report the formation of MXene compound with Mo as $M$-element, obtained through selective etching of $\mathrm{Ga}$ bilayers in the MAX phase related material, $\mathrm{Mo}_{2} \mathrm{Ga}_{2} \mathrm{C}$, from paper II. It should be mentioned that removal of the Ga layers from the $\mathrm{Mo}_{2} \mathrm{GaC} \mathrm{MAX}$ phase was unsuccessful, probably due to the stronger bonding between the Mo and Ga layers in this system. 

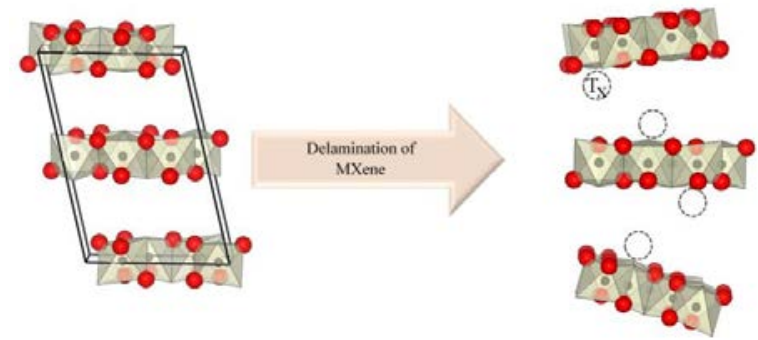

Figure 6 Schematic illustration of delamination of MXene and production of single flakes. $T_{x}$ denotes the termination groups after the etching process.

\subsection{Production of single flake MXene}

Etching of a MAX phase will typically result in a multilayered MXene samples where single layers are connected via Van der Waals forces. However, to obtain single flake MXene, it is required that the etched sample is delaminated, meaning that the individual MXene layers within the stack of sheets gets separated from each other. For that purpose, an organic base, normally, Tetrabutylammonium hydroxide $(\mathrm{TBAOH})$ with the chemical formula $\left(\mathrm{C}_{4} \mathrm{H}_{9}\right)_{4} \mathrm{NOH}$, is utilized, which will intercalate into the compound, and aid in the sheet separation. The disadvantage of using this chemical is that the molecules won't rinse off that easily even after rinsing the suspension with ethanol and distilled water, several times, thus it contaminates the produced sample. Another option is therefore to etch the sample using $\mathrm{LiF}-\mathrm{HCl}$, which make the delamination and exfoliation process, most often, spontaneous using solely distilled water.

\subsection{Properties and applications}

MXene compounds have shown high promise for applications such as in electrodes for energy storage devices, e.g., lithium batteries [56] and supercapacitors [61, 85], for electromagnetic interference shielding [86-88], water purification [89], nuclear waste management [90, 91], photocatalysis [92], biosensors [93, 94], antibacterial activity [95] and lubrication [96, 97], amongst many others.

Surface terminations and intercalations can be a method to tune and tailor the properties, such as the electrical behavior of these materials, since different functionalization lead to different inter-layer spacing, altering their bandgap energies, thus making these materials either a conductor, semiconductor, or an insulator, as suggested by several theoretical studies $[70,75$, 
76, 78]. Furthermore, theoretical studies on the $\mathrm{Mo}_{2} \mathrm{C}$ phase suggests very promising thermoelectric properties [98].

In addition, defects and vacancies within these 2D compounds can also impact their e.g., electronic and magnetic properties [64, 99, 100], which motivates synthesis of a 2D MXene with ordered vacancies, obtained in a controlled manner.

Another new field of research for MXene materials is hydrogen evolution reaction (HER), where MXenes can be utilized as an electrocatalyst for the process [101, 102].

In Paper VI, I reported synthesis of a new MXene with ordered divacancies, $\mathrm{W}_{1.33} \mathrm{C}$, where HER measurements show a very promising catalytic behavior. 



\section{MATERIAL SYNTHESIS}

In general, material synthesis is divided into two main categories; thin film synthesis and bulk sintering. Thin films are normally produced when elements/material in gas/plasma are transferred onto a, most often, a crystalline surface (substrate). This process is called deposition and the resulting thin film structure/composition depends on several factors e.g., temperature, the deposition rate of the material, and the structure of the substrate material. Each of these factors can also have an impact on the crystal orientation, defect formation, and stress induced within the films. Thin films are typically grown via two main processes, either chemical vapor deposition (CVD) where volatile chemicals are deposited onto the substrate surface, or physical vapor deposition (PVD), in which vaporized target materials condensate onto a solid substrate. The second part of the thesis, concerns bulk synthesis, where a powder sample with a certain composition and microstructure is obtained through heating and densification of a mixture of different elemental powders.

In this thesis, depositions of the thin films are performed using magnetron sputtering which is a PVD process. The bulk synthesis is performed using pressureless sintering.

\subsection{Magnetron sputtering}

All the thin films in this thesis were synthesized using a DC magnetron sputtering system equipped with three magnetrons. Here, the cathode electrode is the sputtering target, which should ideally be an electrically conductive material to prevent the accommodation of charges on the surface, which will, in turn, hinder the surface bombardment by ions. An inert gas, typically argon, is employed as the active gas in the sputtering system. The Ar atoms will get ionized either by collisions with other Ar atoms or by the secondary electrons produced in the vacuum chamber. The energy of these ions will be determined by the negative bias voltage applied to the target, which will make these ions accelerate towards the target materials. The outcome of such collisions is either the implantation of the Ar-ions into the target or ejection of the target atoms, caused by the momentum transfer. Some of the atoms emitted from the target land on the substrate surface, to form a film. Increasing the energy of the Ar-ions will increase the number of emitted target atoms and thus the sputter yield, which is the ratio between the number of ejected target atoms and that of the colliding ions. The yield also depends on the 
material that the target is composed of. In a normal case, the ejected electrons fly away from the cathode. Hence, to obtain a sustainable and more intense plasma as well as a higher deposition rate, a magnetic field is introduced into the system. Placing magnets under the target aids to concentrate the plasma, by electron spiraling around the magnetic field lines above the target surface. Increased electron/ions concentration close to the target increases the sputtering rate (flux), which in turn may increase the film growth rate. Figure 7 illustrates the DC magnetron sputtering system with three magnetrons used for synthesis of thin films presented in this work.
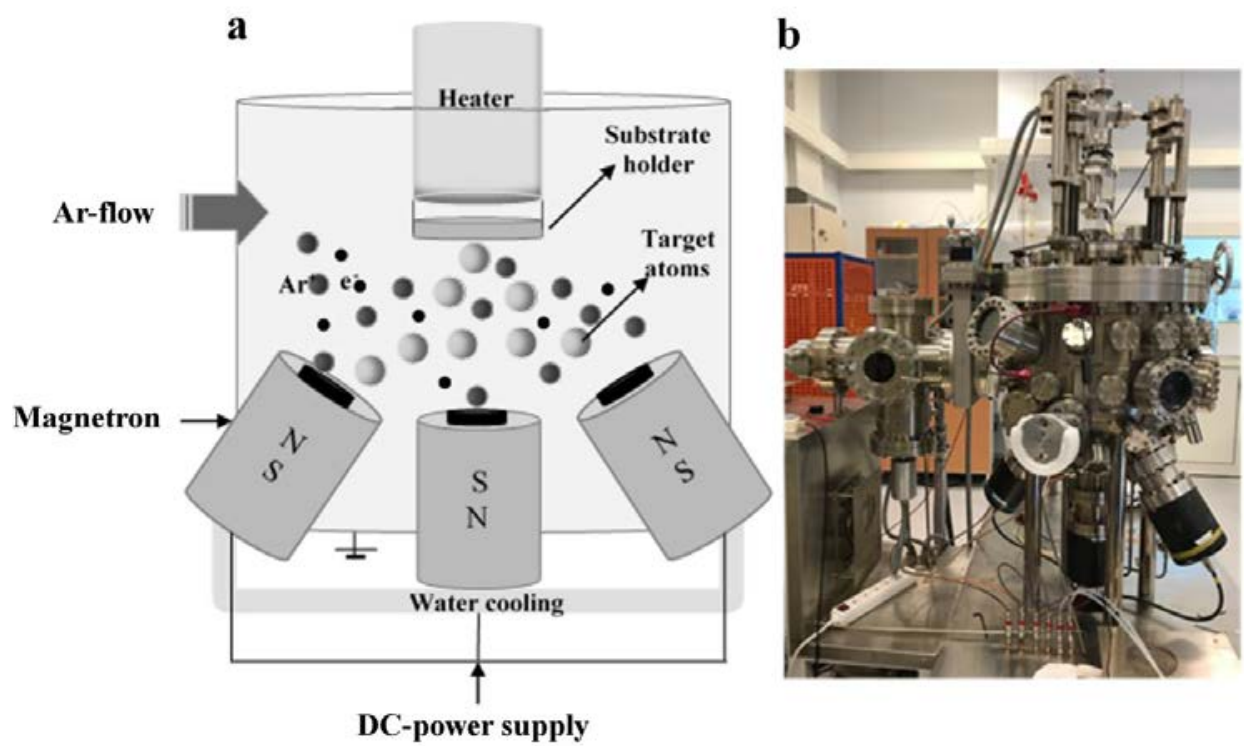

DC-power supply

Figure 7 a) Schematic illustration of three magnetron sputtering system b) an image of the DC sputtering system used for synthesis of the thin films presented in this thesis.

There are two types of magnet configurations in sputtering systems; balanced and unbalanced, which are illustrated in figure 8. In the former type, the inner and outer magnets have the same strength which makes the plasma confined close to the target surface. Further, an unbalanced configuration is formed when the inner and outer magnets have different strength. If the inner magnet is stronger that the outer (type I) then the ion flux close to the substrate is low. Thus, an unbalanced (type II) configuration allows a higher ion flux to reach the substrate, since the 
stronger outer magnets compared to the inner one, makes the magnetic field lines to stretch towards the substrate.

a

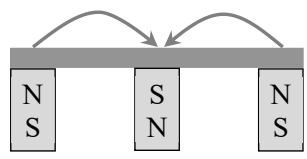

b

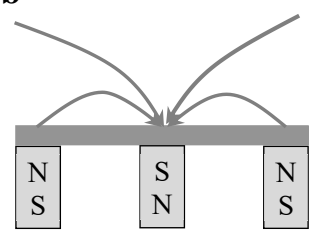

c

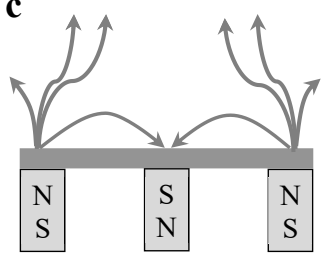

Figure 8 Schematic illustration of the three different magnet configurations in sputtering systems, a) balanced, b) unbalanced (type I) and, c) unbalanced (type II).

\subsection{Nucleation and growth}

There are several steps of film growth; such as adsorption of the atoms on the substrate surface, surface diffusion, the formation of chemical bonds between either target atoms themselves or between the substrate and targets atoms, formation of islands and grains, in turn forming the microstructure of the material, including defects and grain boundaries, etc. In general, the mobility of the adatoms have a great impact on the resulting microstructure of the film. Further, atoms can also be reflected from the substrate surface. The desorption or adsorption of the target atoms depend on several parameters; the flux of the incoming atoms, and the trapping probability or sticking coefficient of these atoms. The crystal structure as well as the diffusion rate of the target atoms are among the parameters that affect the growth mechanism of the thin films. An incoming atom will influence the bonds between the substrate atoms and that may increase the surface energy of the substrate. If the atom diffuses to a low energy site, provided that it has enough time and energy to do that, the surface energy will be reduced. One factor that has an impact on the diffusion rate is the temperature of the substrate. The higher this temperature is, the higher the diffusion rate will be.

In the following paragraph, the three mechanisms are explained through which nucleation and growth of a film on top of the substrate occur;

Volmer-Veber type (islands), in which adatoms will form small clusters or island on the substrate surface due to a stronger bonding between the target atoms than between the target atoms and the substrate. 
Frank-van der Merwe (layered), is when the adatoms bond strongly to the substrate and thus monolayer(s) can form a uniform thin film over the substrate surface.

$>$ Stranski-Krastanov (layered-islands), is when the adatoms initially form a uniform layer on the substrate surface, after which a few monolayers turn into an island-type structure. This might happen when the first monolayers are strained so that they can fit the substrate structure, but they will eventually relax and grow into smaller clusters.

A schematic representation of these three growth processes is demonstrated in figure 9.

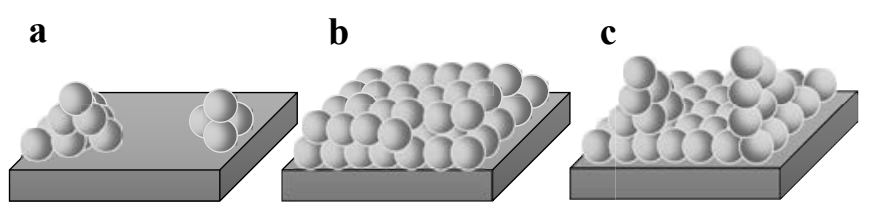

Figure 9 Schematic illustration of different growth modes; a) Volmer-Veber, where islands will be formed on the substrate, b) Frank-van der Merve, in which a uniform film will be obtained and c) Stranski-Krastanov, where after one or several uniform layers, islands and clusters will be formed on top.

The substrate acts as a template in the deposition processes and it is normally chosen to structurally match the film to be grown, i.e., to have a comparable in-plane lattice parameter. In this case, the film will likely be epitaxially grown on the substrate, which means that the crystal has a defined orientation, in both in-plane and out-of-plane directions. Further, any mismatch of the lattice parameters will lead to induced stress/strain in the deposited film, which in turn may affect its lattice parameter. If the substrate and the deposited film consist of different materials, the film is then said to be heteroepitaxially grown on the substrate (as opposed to the homoepitaxial growth when both substrate and the film are of the same material).

Further, dislocations, defects, and grain boundaries in the substrate can greatly influence the nucleation and growth mechanisms and thus the quality of the deposited film. There is a study by Schroeder et al. [103] on different $\mathrm{MgO}$ substrates provided by six different suppliers, where they show that a large number of these substrates consist of several domains rather than being single crystals. Hence, careful measurements on the substrates are required to evaluate these prior to the deposition process, if a film of very high structural quality is required.

The sublimation rate of the deposited materials is another parameter influenced by the growth temperature. For materials with a high sublimation rate, the deposition rate will decrease at 
elevated temperatures, due to decreased sticking coefficient ${ }^{1}$. This means that of some elements do not necessarily stick to the substrate/film surface during the film growth.

\subsection{Thin film deposition of MAX phases}

When growing thin films of MAX phases, the parameters which strongly influence the quality and the structure of the films need to be taken into consideration, e.g., the working pressure, the deposition temperature and the power applied to the different targets. Further, depending on the atomic weight, temperature and sublimation rate of each element, the power/current need to be optimized.

Another issue when dealing with MAX phases is the growth of competing phases. These are binary and/or ternary phases which may be more stable or have a structure close to that of the respective MAX phases. Hence the stability of the MAX phases with respect to their set of competing phases are of importance for synthesis of high purity samples.

Prior to each deposition, the substrate is annealed at the growth temperature to attain a uniform temperature on the surface. Rotation of the substrate is also essential for obtaining a homogeneous film. For MAX phase synthesis, typical growth temperatures are between $\sim 450{ }^{\circ} \mathrm{C}$ and $\sim 1000{ }^{\circ} \mathrm{C}$, exemplified for $\mathrm{V}_{2} \mathrm{GeC}, \mathrm{Cr}_{2} \mathrm{AlC}$ and $\mathrm{Ti}_{4} \mathrm{GeC}_{3}$, respectively [3, 22, 104]. A high growth temperature is needed to facilitate diffusion of the atoms into the layered structure. For the high-quality samples in the form of epitaxially grown films, the $000 l$ planes are oriented out of the substrate plane. Substrates with a hexagonal structure, or a cubic crystal cut in a (111) orientation, are required in order to obtain high-quality crystalline epitaxial layers. For instance, the in-plane parameter of $\mathrm{MgO}$ in (111) orientation has $a / \sqrt{2} \sim 2.98 \AA$, where $a$ is $\sim 4.2 \AA$, which is comparable with that of the $\mathrm{Mo}_{2} \mathrm{GaC}$ phase with an $a$ parameter of $\sim 2.97 \AA$. In paper I, we investigated how the crystal structure and quality of three different substrates, i.e., $\mathrm{MgO}(111), \mathrm{Al}_{2} \mathrm{O}_{3}(0001)$, and $6 \mathrm{H}-\mathrm{SiC}(0001)$, can influence the relative lattice parameters of the $\mathrm{Mo}_{2} \mathrm{GaC}$ thin films. The epitaxial relationship of the films and $\mathrm{MgO}(111)$ substrate in the in-plane and out-of-plane directions is determined to be $\mathrm{Mo}_{2} \mathrm{GaC}[11 \overline{2} 0]|| \mathrm{MgO}[10 \overline{1}]$ and $\mathrm{Mo}_{2} \mathrm{GaC}[0001]|| \mathrm{MgO}[111]$, respectively.

\footnotetext{
${ }^{1}$ The ratio between the number of atoms that adsorb onto the substrate and the total number of atoms arriving the substrate surface.
} 
In spite of the fact that the "in-plane parameter" of $\mathrm{Al}_{2} \mathrm{O}_{3}(0001)$ and $\mathrm{MgO}(111)$ are comparable, synthesis of $\mathrm{Mo}_{2} \mathrm{GaC}$ phase was only possible on the $\mathrm{MgO}(111)$ substrates. No sign of this phase could be seen on $\mathrm{Al}_{2} \mathrm{O}_{3}(0001)$ or $6 \mathrm{H}-\mathrm{SiC}(0001)$. However, more studies using different deposition conditions are required to fully establish this outcome. Nevertheless, such nucleation problems can arise from, for instance, a non-stoichiometric MAX phase, or a slight difference between the in-plane parameters of the MAX phase and the substrate.

Another challenge was the use of a liquid target, i.e., Ga, with a melting point of $\sim 30{ }^{\circ} \mathrm{C}$. As it becomes liquid during synthesis, it needs to be placed in a vertical position underneath the substrate to avoid any spillage of the target material into the chamber. With time, contamination from other targets can get into the Ga target and partially solidify the surface. Further, the discharge gas can also accumulate into the target, causing it to burst under the synthesis process which, in turn, can influence the crystal quality of the deposited film in terms of its smoothness and crystal structure. This can, however, be handled using a lower power, i.e., increasing the cooling efficiency of the target.

Using compound targets is another challenge for thin film synthesis, due to the difficulty of attaining the correct composition, when for example two elements in the target have different sublimation rates (or vapor pressure). It creates issues for higher deposition temperatures. In such cases, the composition of the target after some time of operation may deviate from the initial ratios. For materials with high vapor pressure, the higher the temperature gets at the substrate, the lower the sticking coefficient.

In paper IV and V, compound targets of Mo:Mn or Mo:Sc, with ratios of 1:1 and 2:1, repectively, were utilized. In the first case, although the two elements have slightly different vapor pressure, the ratio of the two elements within the deposited films were as in the target, due to the rather low deposition temperature, i.e., $\sim 550^{\circ} \mathrm{C}$. In the latter experiment, the two elements, i.e., Mo and Sc, had almost similar vapor pressure, and thus the composition of the target/film remained very similar throughout the experiment.

It should be kept in mind that due to different vapor pressures, energy distribution, and surface binding energy for different elements during co-sputtering, the composition of the resulting film might be off from that of attempted initial ratios. For instance, $\mathrm{Al}$ has a high vapor pressure, and thus at high deposition temperature, $\geq 700{ }^{\circ} \mathrm{C}$, it requires higher power to compensate for the evaporation loss during the synthesis. 
All the deposition processes performed in this thesis are optimized by performing a set of room temperature growth rate calibrations on each target. The thickness as well as the density of each film is determined using X-ray reflectivity measurements, and the atomic flux from each target can be calculated and related to respective applied power. There are tabulated values for sputtering yield of the elements at different voltages, which can be used to obtain the flux out of the target at different powers and thus determine how much of the target material will reach the substrate surface. A more detailed explanation regarding the calibration processes is given by Ingason et al. [105].

\subsection{Bulk synthesis}

Sintering in general refers to coalescence of two or more materials without melting. The result, i.e., the microstructures or the quality of the sample, depend on e.g., particle sizes, sintering temperature and time, the rate of heating or cooling the system, the ratio of the elements mixed in the sample and also the atmosphere (and pressure) in the sintering furnace. There are two types of sintering processes; solid state sintering, in which, the elements are all in solid phase, and liquid state sintering, where one or a several elements are in liquid form. The sample undergoes two processes during sintering; densification and grain growth. In this thesis, all bulk synthesis was performed utilizing a solid state pressureless sintering method, and thus a brief description on synthesis of these materials will be provided in the following section.

\subsubsection{Solid state sintering}

Sintering has a few stages; bonding of the particles, production of internal pores, densification of the pores, and grain growth.

Densification or shrinkage occurs when elements diffuse from the grain boundaries produced within the system, which can also lead to induce stress within the sample if the process occurs at a very high rate. On the other hand, if the transport of the material through the system is via the particle surface (lattice diffusion), redistribution of the elements occurs without any densification. In this case, the sample will be more porous, which also influence the grain growth and in turn the microstructure of the compound.

The most critical parameter for sintering is the size of the particles which will affect the time and the rate of the diffusion process and thus impact the quality of the sample. Hence, the 
smaller particle sizes give rise to higher sintering rate and vice versa. In general, the size of the powders is given as mesh sizes. For instance, graphite powders, used in this thesis, had a particle size of -200 mesh, which means that more than $90 \%$ of these particles should go through a 200-mesh sieve, which, in turn, corresponds to $74 \mu \mathrm{m}$.

Another important parameter is the sintering temperature; the higher the temperature is, the higher the rate of sintering and chemical reactions between the powders. In this case, the material would also be viscous, which makes it easier for the elements to flow within the grain boundaries i.e., the lattice diffusion dominates for higher sintering temperatures due to its higher activation energy. The downside of using very high sintering temperatures is when materials with high vapor pressure are used. Hence, in such experiments, a higher ratio of those elements in the powder mixture can compensate the possible loss of these materials during the synthesis process.

For the pressureless sintering, the sample will be put in an alumina crucible which, in turn, is placed inside an alumina tube in a sintering furnace. The sample is then heated up to a certain temperature under constant Ar flow to prevent oxidation of the powders. Depending on the diffusion rate or the vapor pressure of the elements in the sample, the sintering conditions e.g., temperature, time, ratio of the elements, etc., can be optimized for improving the quality of the sample. Figure 10, shows a schematic illustration of a pressureless sintering furnace.

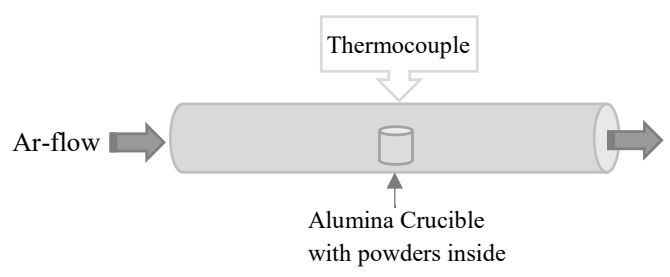

Figure 10 Schematic drawing of a bulk sintering furnace 


\subsection{Bulk vs thin film synthesis}

When choosing between MAX phase synthesis from sintering processes or thin film depositions, one should be aware of the characteristics as well as the limitations for respective technique. In the case of thin film synthesis, the energy, apart from that obtained through heating, is provided by energetic ion bombardment, which make it possible to achieve a process far from thermodynamically equilibrium, for potential realization of metastable materials. This, in turn, allows a lower synthesis temperature than that of the bulk sintering. Further, the defect levels and growth of other impurity phases in the films is more easily controlled, which is due to the increase in diffusion rate of surface atoms during the synthesis process, which, in turn, may provide larger grain sizes within deposited films. Growing close to single crystal or high crystal quality films in terms of structure and composition and in a certain orientation, is hence more common in thin film growth, even though really large single crystals ( $\mathrm{mm}$ and above) can only be obtained from bulk synthesis. Therefore, thin film growth is a common method employed when investigating the intrinsic properties of the deposited materials, e.g., electrical and magnetic behavior.

Bulk synthesis, on the other hand, occurs in a thermodynamically equilibrium state in which the heating is the only source of energy provided to the system. Formation of grain boundaries, defects, impurity phases, and traces of non-reactive elements are some of the inherent challenges of such process. Therefore, a longer sintering temperature and/or time is required for increasing the diffusion and solubility of some elements. However, the process has the benefit of realizing larger samples, which can, in turn, be utilized to study various properties. The other advantage of powder samples is that these do not require any sample preparation for characterization, such as for transmission electron microscopy analysis. 



\section{MATERIALS CHARACTERIZATION}

For characterizations of the structure and composition of the synthesized materials, and to be able to optimize the synthesis conditions, various analytical techniques are performed on the samples. A brief description of the utilized methods in this thesis, is presented in the current chapter.

\subsection{X-ray diffraction}

A fast and common method applied for structural determination of thin films and bulk samples is X-ray Diffraction (XRD), where an X-ray beam, irradiates the sample. The X-rays have a wavelength in the range $0.5-50 \AA$, which is of the same order as the atomic distances within the crystals, and are generated using a filament of a heavy element, e.g., molybdenum or tungsten. This will be heated and creates electrons that would collide with a source, most often from $\mathrm{Cu}$, and generate X-rays. In this case, both $\mathrm{K}_{\alpha}$ and $\mathrm{K}_{\beta}$ are generated. However, using a Ni-filter will absorb the unwanted $k_{\beta}$ radiation and result in a coherent and monochromatic X-ray beam. This irradiation results in an interference from the scattered X-rays and a diffraction pattern is obtained.

To obtain constructive interference from a crystal plane, the angle of the incident and the diffracted beam, with respect to the sample surface, should be equal, and the Bragg's law, $2 d \sin \theta=n \lambda$, fulfilled. This law, states that the path difference, $2 d \sin \theta$, should be equal to a multiple, $n$, of the wavelength, $\lambda$, where, $d$, is the plane spacing of the crystal lattice and, $\theta$, is the angle between the planes and the incident beam. Figure 11 is a schematic illustration of the crystal planes diffracting the incoming X-rays. 


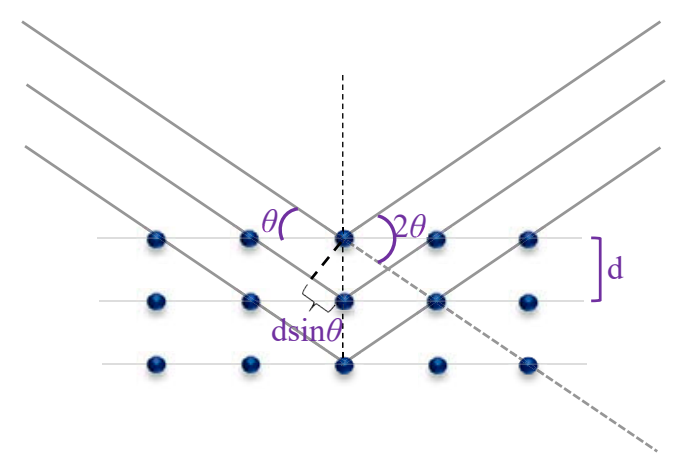

Figure 11 Schematic drawing of X-ray diffraction $(\theta-2 \theta)$.

There are some other factors, apart from the Bragg's law, which influence the diffraction obtained from a certain sample; one is the structure factor which depends on the crystal structure and determines which planes would give rise to diffraction and diffractions from which planes are forbidden. Other factors that might affect the obtained diffraction pattern and the relative intensity of the peaks are, e.g., absorption factors, preferred orientation or texture of the sample. Hence, depending on the structure, i.e., the atomic positions in the lattice and the quality of the crystal, the peak positions and the shape of the peaks and, also the intensity will be influenced. Most common information provided by XRD includes identification of crystal structures and the phases present in the studied samples. In the case of thin films, information regarding e.g., thickness, density and preferential orientation of the phase can also be obtained. To extract such information, the sample must undergo different types of measurements which can be provided in different modes, some of which are briefly described in the following;

\subsubsection{Symmetrical $\theta-2 \theta$ measurements}

In this mode, the angle of the incident and the diffracted beam remains the same and the $2 \theta$ angle is scanned. Here, the planes investigated are those parallel to the sample surface. This technique is widely used for identification and verification of the MAX phases, because diffraction from the basal planes of this compounds, i.e., the planes parallel to the $c$ direction, are observed. Hence, these measurements provide a direct measure of the $c$-lattice parameter of these materials. One should bear in mind that the hexagonal structure of the MAX phases only allow for diffraction from the even planes of the lattice, that is when the sample is an epitaxially, oriented thin film. In the case of bulk samples (powders), due to their polycrystallinity, i.e., grains with different orientation, a symmetric $2 \theta$ measurement, would give rise to a more 
complicated scan, where all planes parallel to the surface plane, contribute to the diffraction pattern. Furthermore, information regarding the grain size within the film can also be provided by using the full width at half maximum (FWHM) of the obtained peaks.

For the $(\theta-2 \theta)$ measurements performed in this thesis, the source is in "line focus" mode with a hybrid mirror and a $0.27^{\circ}$ parallel plate collimator at the incident and the diffracted beam side, respectively.

In figure 12, a typical diffractogram obtained for a $\left(\mathrm{Mo}_{0.5} \mathrm{Mn}_{0.5}\right)_{2} \mathrm{GaC}$ thin film is shown. The presence of a more intense 006 peak compared to the $\mathrm{MgO}$ substrate peaks, observed in the scan, is because the alignment is performed on the phase plane and not the $\mathrm{MgO}$, due to a very small offset between the substrate (111) plane and the basal planes of the phase.

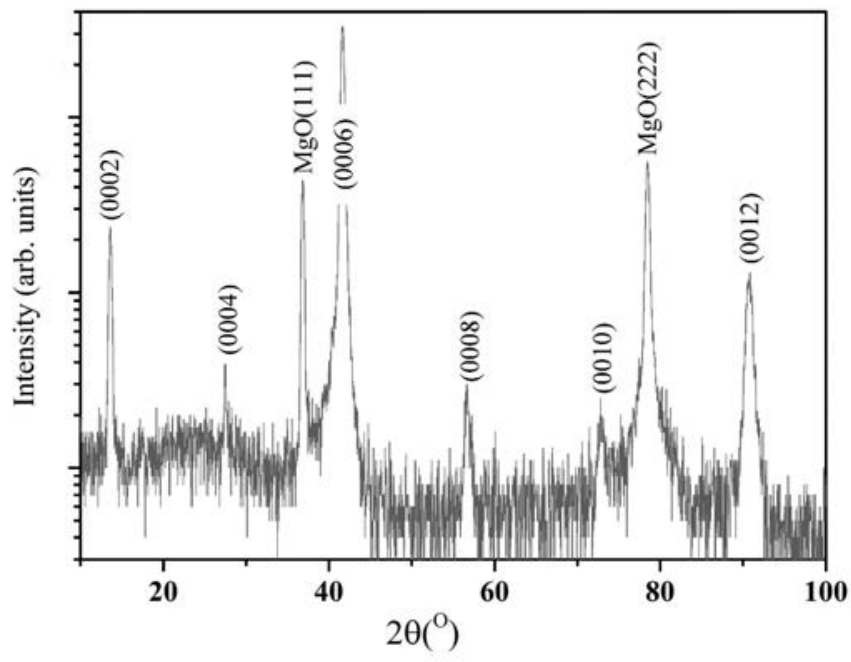

Figure $12 \theta-2 \theta$ XRD scan from a (MoMn $)_{2} \mathrm{GaC}$ thin film. 


\subsubsection{X-ray reflectivity}

By using this method, the thickness, density and the roughness of the film can be determined. The optics used in this operational mode are the same as for the symmetrical $\theta-2 \theta$ measurements. Here, the scan originates from the reflected X-ray beams interference at interfaces between the layers with different refractive indices. In this case, the incident and the diffracted angles are kept the same with a very low $\theta$, and the $2 \theta$ is usually scanned between $0-10^{\circ}$. Figure 13 shows a typical XRR scan obtained for a $\sim 50 \mathrm{~nm}$ MAX phase. It is worth to mention that the reflectivity measurements can only be obtained for relatively thin films (less than $150 \mathrm{~nm}$ ) with smooth surfaces. Moreover, the critical angle i.e., the point where the intensity starts to drop is a measure of the density of the film, e.g., the larger the critical angle, the denser the film is. The shape of the fringes, i.e., the period and the amplitude of oscillations and slope of the scan determine the thickness as well as the roughness of the sample. For instance, the narrower the fringes are, the thicker the film is and the steeper the scan is (i.e., the faster the reflected X-rays decreases), the rougher the sample would be.

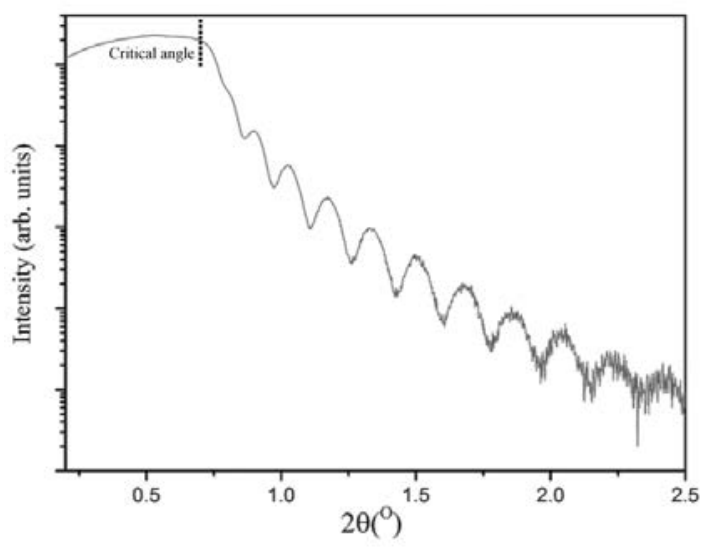

Figure 13 XRR scan for $\mathrm{a} \sim 50 \mathrm{~nm}$ thick $(\mathrm{Mo}, \mathrm{Mn})_{2} \mathrm{GaC}$ thin film. 


\subsubsection{Pole figure measurements}

This mode is used when the crystal quality of a film and its orientation with respect to the substrate need to be determined. Further information regarding the presence of possible impurity phases or other differently oriented crystal grains, tilted grains, can also be obtained utilizing this technique. These kind of measurements, are usually performed with the source in the "point focus" mode and an X-ray lens replacing the hybrid mirror at the incident beam side. There are two additional axes defining the geometry of the sample, the azimuthal axis, $\varphi$, which is between $0-360^{\circ}$ and the sample tilting axis, $\psi$, which varies between $0-( \pm) 90^{\circ}$, illustrated in figure 14. In this mode, the diffraction angle $(2 \theta)$ is kept constant (thus only one d-spacing is being studied) while $\varphi$ is scanned at different $\psi$ angles.

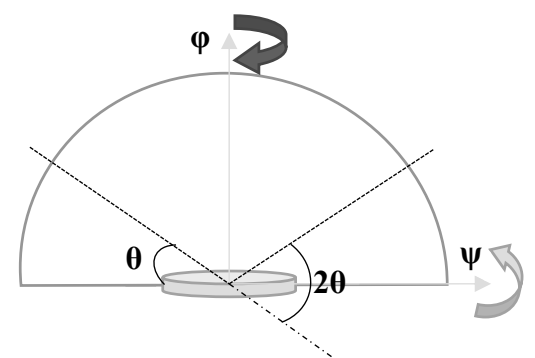

Figure 14 Schematic illustration of a pole figure measurement setup.

A pole figure of the $(0006)$ plane $\left(2 \theta \approx 40.3^{\circ}\right)$ for a $\mathrm{Mo}_{2} \mathrm{GaC}$ MAX phase is presented in figure 15. This measurement was performed to confirm that the broadening of the basal plane peaks obtained in the symmetrical $\theta-2 \theta$ measurements, is due to the overlap of these peaks with the (1013) planes, see paper I. As it is apparent from the figure, there are six spots around the midpoint at $\sim 60^{\circ}$, indicating the presence of the grains grown in the (10 $\overline{1} 3$ ) direction out of plane with respect to the substrate, which has a six-fold symmetry. This could also be confirmed by calculating the angle between the $(10 \overline{1} 3)$ and $(0006)$ planes $\left(\sim 60^{\circ}\right)$, using the following equation,

$$
\cos \theta_{p}=\frac{4}{3 a^{2}}\left[h_{1} h_{2}+k_{1} k_{2}+\frac{1}{2}\left(h_{1} k_{2}+h_{2} k_{1}\right)+\frac{3 a^{2}}{4 c^{2}} l_{1} l_{2}\right] d_{1} d_{2}
$$

where $\cos \theta_{p}$ is the angle between the two planes $\left(d_{1}=d_{(h l k l l l)}\right.$ and $\left.d_{2}=d_{\left(h_{2 k 2 l 2)}\right)}\right)$, with the $\left(h_{1} k_{l} l_{l}\right)$ and $\left(h_{2} k_{2} l_{2}\right)$ as their corresponding Miller indices and $a$ and $c$ as the in-plane and out-of-plane lattice parameters. 
If the film only consisted of epitaxially grown layers, with no tilted grains, or there was a considerable difference between the d-spacing of the (0006) and (1013) planes, then, the pole figure would only contain the middle spot.

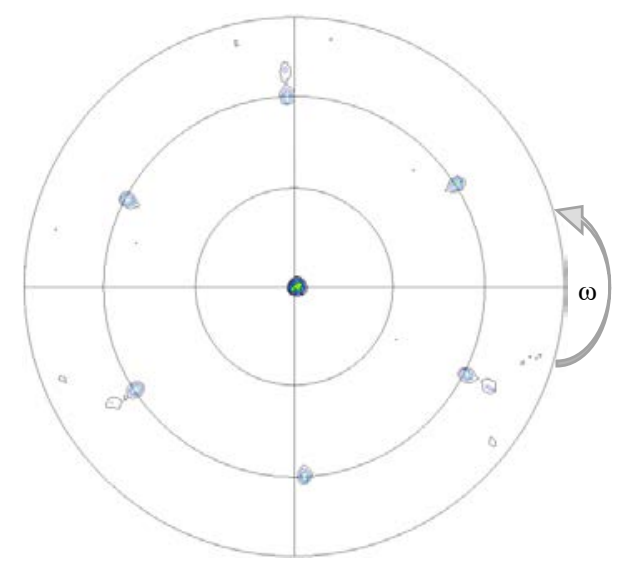

Figure 15 Pole figure of the (0006) plane from a $\mathrm{Mo}_{2} \mathrm{GaC}$ MAX phase.

\subsection{Rietveld refinement}

The XRD scan for bulk material contains all possible peaks from different crystal planes, since powders samples are typically polycrystalline. Hence, in order to determine the quantity of the major phase which is usually obtained as the weight percentage and, to identify the possible impurity phases within the sample, a structure profile analysis program, the so-called Rietveld refinement measurement, is used to analyze the XRD scans.

The initial fitting of the XRD data, e.g., identifying the impurity phases in the sample, is normally done, using a program called High score which has a broad structural database over all experimentally synthesized materials.

In order to obtain the starting input parameters for the main phase, if unknown, e.g., space group, symmetry, atomic positions, etc., the sample is analyzed using transmission electron microscopy or the data obtained by theoretical calculations, if such exists. The idea is to analyze the "measured" scan by Rietveld refinement using FullProf code [106] until it fits with the "simulated" scan which is when that the residual scan gets as close to a straight line as possible, and for that, the least square method is used.

The main refinement parameters are; the scale factor, which quantifies the weight fraction of the phases within the sample, fitting the absolute intensities of the peaks in the scan, the zero 
shift, which affect the peak positions together with the height alignment of the sample in the measurement. Other factors are, 4-5 background factors, which also can be adjusted manually, using the "linear interpolation between a set background points with refinable heights". Furthermore, a standard reference sample, most often, lanthanum hexaboride $\left(\mathrm{LaB}_{6}\right)$ fine powder, is utilized to obtain the exact broadening caused by the instrumental factors. Other parameters influencing the peak shape are $\mathrm{X}$ and $\mathrm{Y}$ factors, which depends on the crystallite sizes, or stress and micro-strain in the structure. For further improvement of the refinement, atomic positions, preferred orientations, occupancies and B-factors, which depends on the isotropic thermal vibration of the atoms and the lattice parameters of all included phases, can also be fitted.

Figure 16, shows a refined XRD scan of a highly pure $\mathrm{LaB}_{6}$. It has a cubic structure with a lattice parameter, of $4.15695 \AA$, measured with $\mathrm{Cu} k_{\alpha}$ radiation where $\lambda \sim 1.54 \AA$. The measured scan was obtain using a PANalytical X'Pert powder diffractometer, with $\mathrm{Cu}$ source $\left(\lambda_{k_{\alpha}} \approx 1.54 \AA\right)$. The optics utilized for these measurements were a graded Bragg-Brentano HD with a $1 / 4^{\circ}$ divergent and $1 / 2^{\circ}$ anti-scattered slits, in the incident beam side, and a $5 \mathrm{~mm}$ anti-scatter slit together with a Soller slit (with an opening rad. of 0.04) in the diffracted beam side. A $5^{\circ}$ to $120^{\circ}$ continuous scan was performed on the sample using a step size of $0.008^{\circ}$ with a $40 \mathrm{~s}$ time per step.

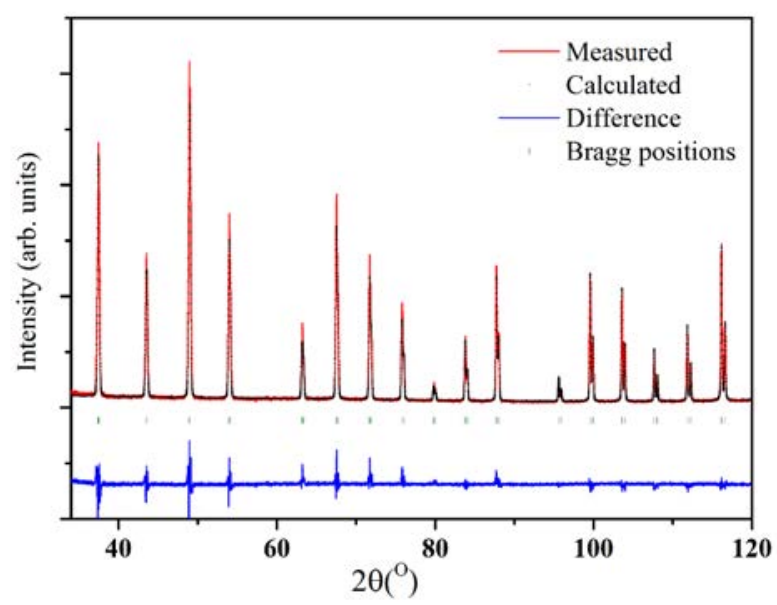

Figure 16 A symmetrical XRD scan for a $\mathrm{LaB}_{6}$ reference powder sample and the measured XRD scan using Rietveld refinement method. 


\subsection{Transmission electron microscopy}

For a more detailed understanding of the crystal structures of the materials, and to be able to characterize these compounds down to the atomic level, transmission electron microscopy (TEM) analysis are performed on the samples, providing information on e.g., microstructure, atomic positions and elemental compositions. This technique utilizes an electron beam, instead of photons, to probe the samples. The advantage of using an electron beam is that high energetic electrons, which have a short wavelength, can provide high spatial resolved images, since their wavelength is in the order of atomic distances in the crystals, $\sim 2 \AA$.

As the name implies, an image is generated by electrons transmitted through a sample and interacting with its atomic species. There are different types of interaction processes involved: unaffected/unscattered electrons transmitting through the matter, elastically scattered electrons, and inelastically scattered electrons. In figure 17, different interaction mechanisms between the specimen and the electron beam are schematically illustrated.

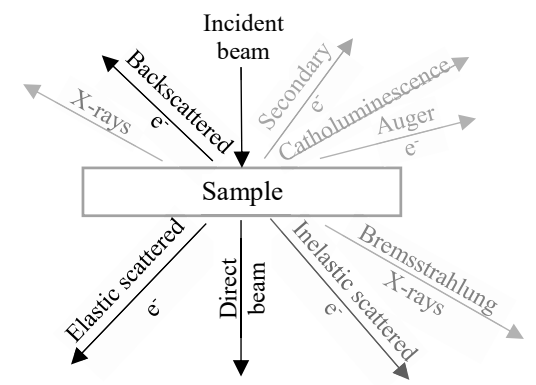

Figure 17 Different interaction processes after an electron beam enters the sample.

In normal TEM measurements, due to the inverse relation between the number of transmitted electrons and the thickness of the film, the unscattered electrons can be used to identify changes in the sample thickness: the thicker the sample, fewer electrons are transmitted through it, resulting in a darker area, and the thinner the sample, the brighter image is obtained as a result of more transmitted electrons. Further, the crystal structure of the phase is normally determined from the diffraction data obtained using electrons scattered elastically within the film. Secondary and Auger electrons, X-rays and lattice vibrations are amongst the outcome from inelastic interactions providing information, for instance, regarding the atomic bonding state of different elements within the film. 
There are two types of electron sources, the thermionic gun (e.g. $\left.\mathrm{LaB}_{6}\right)$ and the field emission gun, FEG (e.g., Schottky). Due to the higher brightness of FEG and its smaller spotsize, this is a better choice when high magnification image is desired. However, the high current of the thermionic guns makes these sufficient for recording lower magnification micrographs.

The various electron interaction outcomes can be used in different TEM measurements modes. Hence, there are several modes of operation used to deduce different type of information regarding the sample of interest. In the following, a brief description of some of these techniques is presented.

\subsubsection{Scanning transmission electron microscopy}

This operational mode is widely employed because of its small and focused probe size. In this technique, the image is generated by the diffracted electrons at a wide range of angles determining the type of the intensity contrast in the obtained micrograph. High-angle diffracted electrons give rise to the so called high-angle annular dark field image, with an induced mass (Z) contrast, whereas the low-angle diffracted electrons produce a bright field image in which the contrast is determined by the different diffraction phenomena.

\subsubsection{Selected area electron diffraction}

To obtain a high resolution image, the sample is ideally aligned along the right crystallographic orientation. This is possible by using the selected area electron diffraction (SAED) image mode, where diffraction from a chosen crystal grain can be obtained. Further tilting of the sample in different directions can aid in obtaining a desired diffraction pattern. Figure 18 shows an electron diffraction of $\left(\mathrm{W}_{2 / 3} \mathrm{Sc}_{1 / 3}\right)_{2} \mathrm{AlC} i$-MAX phase, obtained from [010] zone axis.

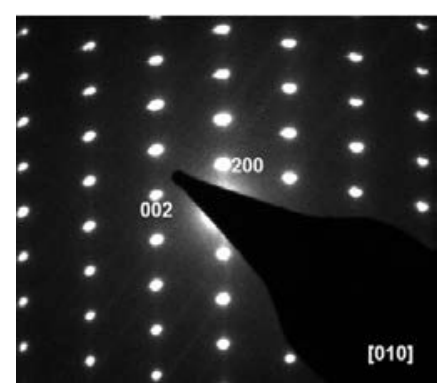

Figure 18 An electron diffraction image from $\left(\mathrm{W}_{2 / 3} \mathrm{Sc}_{1 / 3}\right)_{2} \mathrm{AlC}$. 


\subsubsection{Energy dispersive X-ray spectroscopy}

Compositional and elemental analysis on the sample are carried out using energy dispersive $\mathrm{x}$-ray spectroscopy (EDX/EDS). In this mode, the incident electrons eject the electrons from the inner shell of the sample atoms. These vacancies are filled by the outer shells electrons followed by the emission of characteristic X-rays, providing a spectrum revealing information regarding the type and the amount of the atomic species. Figure 19 shows a micrograph together with the elemental mapping of a $(\mathrm{Mo}, \mathrm{Mn})_{2} \mathrm{GaC}$ thin film.

Most often, a cross-sectional sample is desirable for these measurements, which needs to grinded and thinned manually down to $\sim 50 \mu \mathrm{m}$. Further thinning on the sample is done using an ion beam milling which makes a hole at the center of the sample where the imaging takes place, i.e., at the corners of the holes where the sample is very thin.

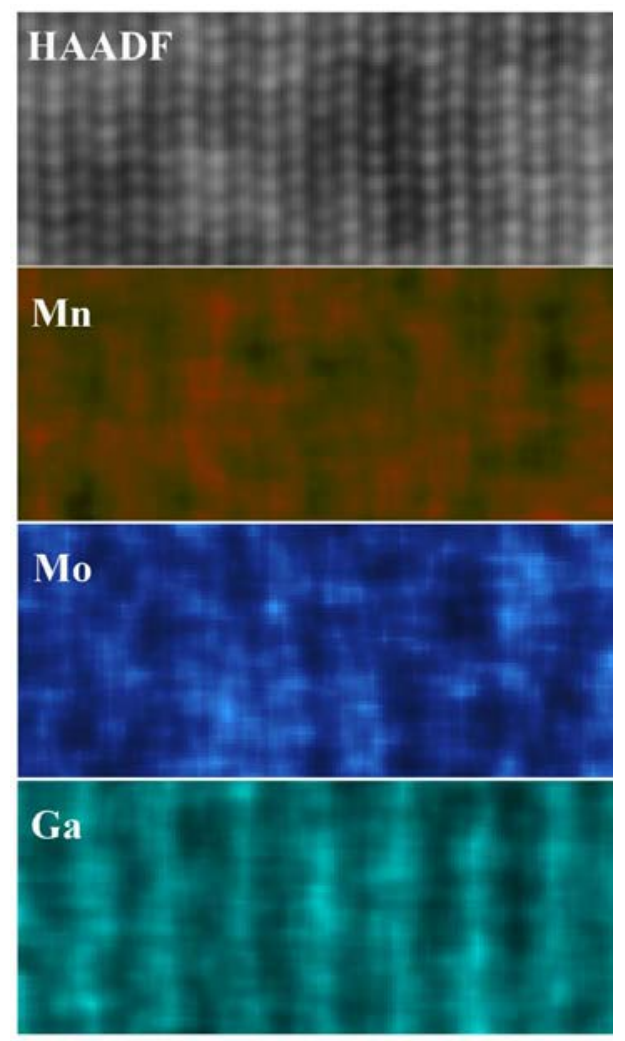

Figure 19 HRSTEM image and EDS mapping of $\mathrm{Mo}, \mathrm{Mn}$ and $\mathrm{Ga}$ from a $(\mathrm{Mo}, \mathrm{Mn})_{2} \mathrm{GaC}$ thin film. 


\subsection{Vibrating sample magnetometry}

To explore the magnetic behavior of the thin films, a vibrating sample magnetometer (VSM) was used. In such measurements, a sample is placed in a uniform magnetic field. The vibration of the sample, after its magnetic moments are aligned along the field direction, will induce a current which is picked up by the "pick-up" coils. This current is proportional to the magnetic moment of the material. An illustration of the VSM system is shown in figure 20.
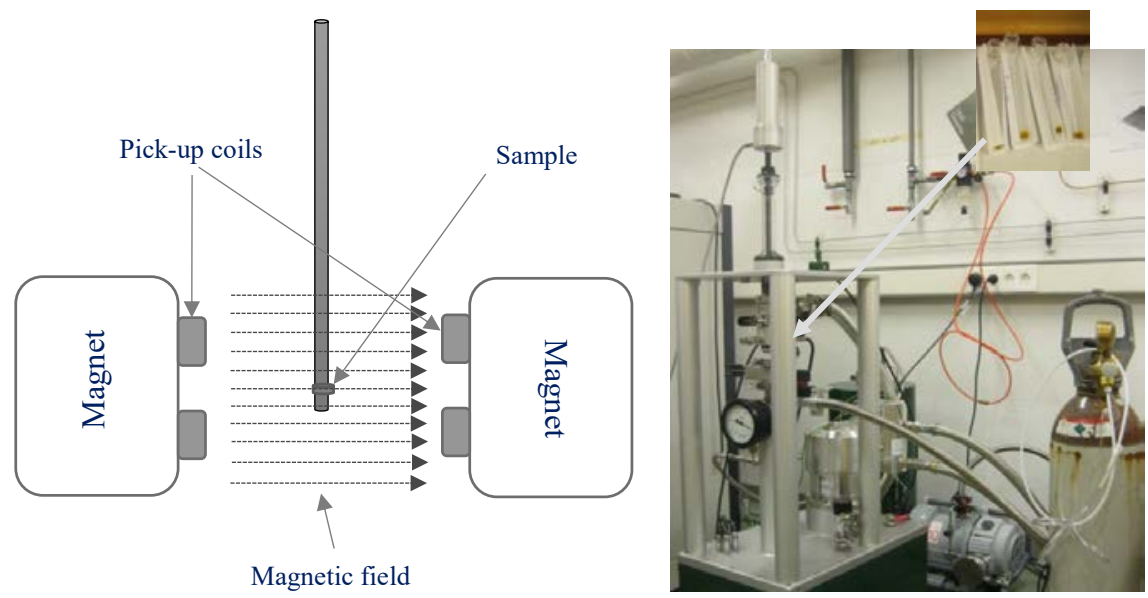

Figure 20 Schematic drawing of a VSM setup together with the setup picture.

In general, the magnetization of a film versus the field strength at different temperature is measured. Figure 21 shows the field dependent magnetization at $5 \mathrm{~T}$ for a $450 \mathrm{~nm}$ thick (Mo, Mn $)_{2} \mathrm{GaC}$ sample. The remanence $\left(m_{r}\right)$ and the magnetization at $5 \mathrm{~T}\left(m_{5 T}\right)$ can be obtained, measuring the magnetization at zero field and at $5 \mathrm{~T}$, respectively. 


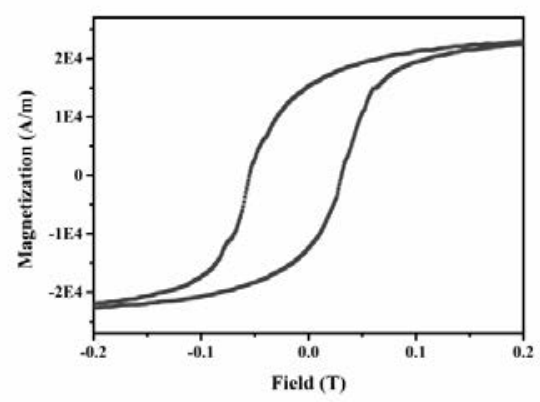

Figure 21 The field dependent magnetization at $5 \mathrm{~T}$ for a $\sim 450 \mathrm{~nm}$ thick $(\mathrm{Mo}, \mathrm{Mn})_{2} \mathrm{GaC}$.

\subsection{Four-point probe measurements}

A common method to measure the temperature dependence of the electrical resistivity of a thin film sample is by utilizing a four-point probe technique. The measurement is performed using four terminals (probes), which are usually made of four conducting wires such as copper, attached equally spaced to the surface of the film. The two outer probes are used for measuring the current while the inner two read the potential drop, see figure 22.

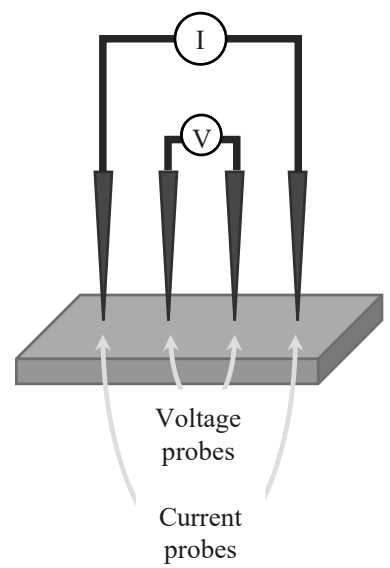

Figure 22 Schematic drawing of a four-point probe measurement.

Performing the measurements employing four probes instead of two is to prevent the electrical current flow through the voltage contacts and spreading the resistance underneath the wires. Further, the volume resistivity of a thin film with thickness of $t$ can be calculated as; 


$$
\rho[\Omega-c m]=\frac{\pi}{\ln 2} \frac{V}{I} t
$$

In the case of a very thin sample, the influence of the thickness on the sample resistance is negligible, hence it can be ignored. In this case, the contact resistance is negligible and can be neglected.

\subsection{Hydrogen evolution reaction}

With the growing environmental problems like global warming and use of fossil fuel, clean and natural energy sources, e.g., solar and wind power are getting more popular. The need for energy production from sustainable sources (solar and wind and beyond) will require new ways of storing energy (electricity is difficult to store on large scale) and offer new ways to fabricate sustainable fuels. By turning excess electricity into chemical fuels (e.g. hydrogen) the energy is stored in the chemical bonds.

In general, the hydrogen production is through reformation and cracking of the hydrocarbon fuels. However, this is also possible through electrochemical reaction where the hydrogen gas is produced using an electrochemical cell containing an electrolyte, which can be acidic or alkaline. Normally, there are three types of electrodes utilized in such lab measurements; counter, reference and working electrodes (lab terminologies). However, commercially there are only two electrodes are used.

Furthermore, if the reaction occurs in an acidic solution, there are three reactions involved;

$$
\begin{aligned}
& H_{a q}^{+}+e^{+} \rightarrow H M \\
& H_{a q}^{+}+H M \rightarrow H_{2} \\
& 2 H M \rightarrow H_{2}+2 M
\end{aligned}
$$

$M$ denotes the catalyst/surface site. In reaction (1), a hydrogen from the solution is attracted to the electrode and combines with an electron to form a hydrogen atom. The formation of the hydrogen gas is either by combining reactions (1) and (2), or via reactions (1) and (3).

For this process, the use of an electrocatalyst material is important, to minimize the overpotential (losses) required for hydrogen production and improve the efficiency of the process. In general, the electronic structure of a material is the key factor for making the material a good catalyst [107]. Thus, the reactivity will depend on the binding energy of $\mathrm{H}$ to the catalyst surface. Increasing the number of active sites in the materials of interest is a way to 
increase the activity of the catalysts, since the main role of the catalyst material is to adsorb the hydrogen atoms and allow for the formation of the molecular hydrogen. Pt and Pd are two of the best candidates for this type of measurements. However, the cost and scarce of these elements on Earth, make the use of other materials essential. Among most studied candidates are $\mathrm{MoS}_{2}[64,108,109]$ and $\mathrm{WS}_{2}$ [110], and a few recent studies also include MXene e.g., $\mathrm{V}_{2} \mathrm{CO}[111], \mathrm{Mo}_{2} \mathrm{C}$ and $\mathrm{Ti}_{2} \mathrm{C}[101]$. 


\section{PHASE STABILITY CALCULATIONS FROM FIRST PRINCIPLES}

The motivation for computer modelling and simulations is to provide information about the system of interest in a very short time scale, for very small details, and at a low cost. It is also a useful method to gain information regarding, for example, electronic and magnetic properties which are difficult to monitor experimentally. Theoretical phase stability calculations can also be used to predict novel materials systems and thus decrease the number of trials for synthesis attempts of phases that are meta- or unstable, i.e., not likely to be realized. Further, it can also be used to find the most stable phases/structures within such system which, in turn, can simplify the experimental studies and be used as a guidance for structural characterization and analysis of the samples.

The simulations performed for this work were done using density functional theory (DFT), implemented in Vienna ab-initio simulation package (VASP) with focus towards stability calculations.

\subsection{Density functional theory}

In order to calculate the stability of a compound, the first step is to identify how the atoms would bind together in the system. This, of course, involves the electrons within the atoms. When an atom with only one electron is considered, any other effects which influences the electronic state than the contribution from the nuclei are excluded. However, in almost all cases, there are more than one electron involved, hence the exchange correlation effects, which is an outcome of the electron-electron interaction would be an essential ingredient to consider and account for in all calculations. The influence of the atomic nuclei can be discarded, since it could be seen as a heavy stationary particle (Born-Oppenheimer approximation). Density functional theory, DFT, is an approach using the electronic density to encounter the electronelectron interaction in the investigated systems. In this case the $3 \mathrm{~N}$ degrees of freedom for electrons in the full Schrödinger equation reduces to 3 degrees of freedom which is the positions of the electrons. 
The key ingredient in DFT is the Hohenberg-Kohn theorems, where the ground state energy of an N-particle system is defined to be a functional ${ }^{2}$ of the electronic density.

Theorem I: For any system of interacting particles in an external potential $V_{\text {ext }}(\mathbf{r})$, the potential $V_{\text {ext }}(\mathbf{r})$ is determind uniquely, except for a constant, by the ground state particle density $n_{0}(\mathbf{r})$.

Theorem II: A universal functional for the energy $E[\mathrm{n}]$ in terms of the density $n(\mathbf{r})$ can be defined, valid for any external potential $V_{\text {ext }}(\mathbf{r})$. For any particular $V_{\text {ext }}(\mathbf{r})$, the exact ground state energy of the system in the global minimum value of this functional, and the density $n(\mathbf{r})$ that minimizes the functional is the exact ground state energy $n_{0}(\mathbf{r})$.

The most challenging factor in in this case would be to calculate the exchange-correlation energy of the N-particle system where the effect of all electrons within the system to the final energy should be considered. For solving this problem, Kohn and Sham proposed an approach where a system with non-interacting particles is in an effective potential field $V_{\text {eff }}(\mathbf{r})$. In the Kohn-Sham approximation, solids were considered as a homogeneous; local density approximation (LDA). This method would work for the systems with slowly varying electron densities, and not for instance, for 3-d metals which have rapidly changing electron densities. For such cases, another approximation, in which the electron densities were allowed to change more rapidly, was proposed, the so called generalized gradient approximation (GGA) [112]. In general, the wave function of solid state materials could be described by a basis set or a wavefunction that has the periodicity of the lattice with some boundary conditions. Hence, these wave functions are expanded in a set of plane waves. There are different approaches when it comes to describe and define these set of plane waves for the system. Some of these approaches are described in the following sections;

\subsubsection{Pseudopotentials}

The potential caused by the motion of the core electrons in an atom as well as the effect of its nucleus, the Coulombic effect, can lead to a very complicated Schrödinger equation to solve. Replacing such effects with an effective potential and thus reducing the number of electrons

${ }^{2}$ It is a function of another function. 
per interaction, so called pseudopotentials, would simplify the Schrödinger equation. Hence, the valence electrons can be described by a set of pseudo-wavefunctions with frozen core electrons, which counts as a part of the rigid atomic nuclei.

\subsubsection{Augmented plane waves}

In this case, the expansion of the electronic wave function is done using a set of augmented plane waves (APW). The atoms are divided into two regions: core $\left(r_{0}\right)$ and interstitial region, with a muffin-tin potential, which is described as follows:

$\mathrm{U}(\mathrm{r})=|r-R| ;$ where $\left\{\begin{array}{l}1 \text { if }|r-R| \leq r_{0} \\ 0 \text { if }|r-R| \geq r_{0}\end{array}\right.$

Here $r_{0}$ is the radius of the sphere surrounding the core region outside which the potential is zero (constant).

\subsection{Theoretical background to phase stability calculations}

How stable a certain crystal structure is compared to other structures is estimated from Gibbs free energy, which can be formulated as

$$
G=E+p V-T S
$$

where $E$ is the internal energy, $p$ denotes the pressure, $V$ is the volume, $T$ is the temperature and $S$ is the entropy of the system, which is a measure of the disorder in the system.

Relaxation of the structure as well as the lattice parameters implies that $p=0$, and $G$ is therefore simply reduced to $G=E$ at $O K$.

The stability of a MAX phase could hence be determined by its formation enthalpy, see definition below, i.e., its energy compared to the energy of the single constituents in their most stable structure and the energy of other compounds, e.g., binaries and ternaries.

\subsection{Optimization of the computational parameters}

For performing first-principle calculations the optimization of the parameters implemented in the program is extremely important. For that purpose, an appropriate potential for each element within the system of interest is determined. Further, the Brillouin zone (BZ) is divided to a set of points, i.e., integrating the reciprocal space which, here, was done using the Monkhorst and 
Pack scheme [113]. In such way, the periodic functions describing the lattice points will be integrated over the whole BZ. The larger the fraction of these points over the BZ, the more accurate will the obtained data become, see figure 23. As it is shown in the figure, the $k$-point describing the " $a$ " and " $b$ " parameters in these calculations are approximately 3-4 times larger than that of the $c$-plane. If the $k$-point density is not sufficiently high, the result will not be converged enough, meaning that the energy either would be too high/low, or the estimation of the volume will be wrong. Another important parameter affecting the calculation is the cut-off energy of the plane waves which is simply the maximum energy that an expanded plane wave can have in order to obtain an appropriate convergence.

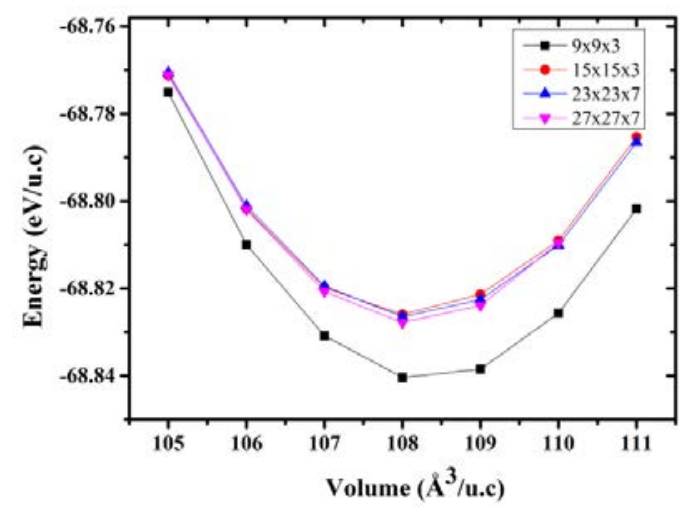

Figure 23 The energy versus volume graph of a hexagonal MAX phase structure at different k-point grids.

Relaxation of the positions of the atoms within the unit cell of the system under investigation is typically performed before evaluation of phase stability and properties. Table II presents the structural parameters of $\mathrm{Mo}_{2} \mathrm{GaC}$, with the phase prototype, $\mathrm{Cr}_{2} \mathrm{AlC}$, introduced in VASP.

Table II. The Wyckoff positions of the atoms within the unit cell.

\begin{tabular}{|c|c|c|c|c|}
\hline Element & Wyckoff position & $\mathbf{x}$ & $\mathbf{y}$ & $\mathbf{z}$ \\
\hline \hline $\mathrm{Mo}$ & $4 \mathrm{f}$ & $1 / 3$ & $2 / 3$ & 0.086 \\
\hline $\mathrm{Ga}$ & $2 \mathrm{~d}$ & $1 / 3$ & $2 / 3$ & $3 / 4$ \\
\hline $\mathrm{C}$ & $2 \mathrm{a}$ & 0 & 0 & 0 \\
\hline
\end{tabular}




\subsection{The linear optimization method used for prediction of phase stability}

Before starting the stability calculations for the system of interest, other combinations of the same elements must be identified in order to find a set of most competing phases within the system (these are phases with the lowest formation enthalpy among all other included competing phases). These could also be binary and ternary phases within the phase diagram of the system or phases that are included in neighboring elements phase diagram. Figure 24 shows the energy diagram of $\mathrm{Mo}_{x} \mathrm{Ga}_{1-x}$. As it is shown in the diagram, Mon $\mathrm{Ga}$ and $\mathrm{MoGa}_{4}$ (a hypothetical phase) are the only stable phases, with respect to Mo and Ga, amongst all. The red stars, above the solid line, shows the metastable phases included in the calculations. The same calculation has been performed for $\mathrm{Mo}_{x} \mathrm{C}_{1-x}$ phases, suggesting that $\beta-\mathrm{Mo}_{2} \mathrm{C}$ and $\gamma-\mathrm{MoC}$, are the most stable phases within that binary group. Some of these results are presented in paper I.

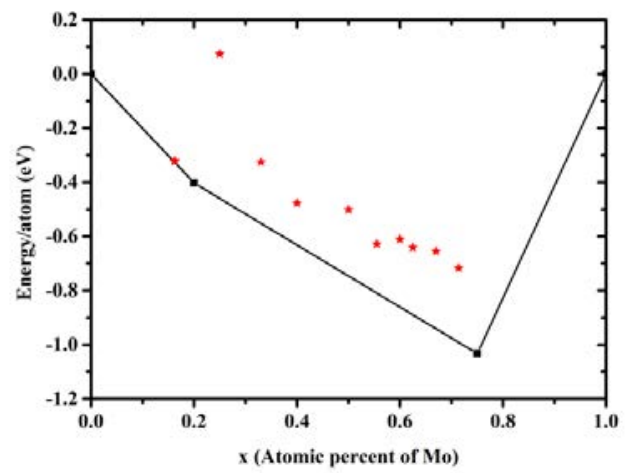

Figure 24 The formation enthalpy of the Mo-Ga binaries with respect to the fraction of $M$-element. The most competing phases in this diagram are $\mathrm{Mo}_{3} \mathrm{Ga}$ and $M o G a_{4} . \mathrm{MoGa}_{4}$ is a hypothetical phase existed in the neighboring element system, $\mathrm{CrGa}_{4}$.

Due to the complexity of finding a set of most competing phases with all possible combinations of phases, a linear optimization method, the so called simplex method, is utilized [114]. Hence, the formation enthalpy, $\Delta H_{M_{n+1} A X_{n}}$ of the MAX phase (per atom) is determined by subtracting the energy calculated for the MAX phase, $E_{M_{n+1} A X_{n}}$ by the energy of the identified set of most competing phases, $E_{c p}$ identified for the system, as follows:

$$
\Delta H_{M_{n+1} A X_{n}}=\left(E_{M_{n+1} A X_{n}}-E_{c p}\right) / 2(n+1)
$$


This follows an approach developed by Dahlqvist et al. $[115,116]$ which has previously been successfully used for prediction as well as verification of MAX phase stability. A recent study on effects from temperature on phase stability predictions for MAX phases, confirms that the stability is primarily governed by the internal energy [117]. 


\section{CONTRIBUTION TO THE FIELD}

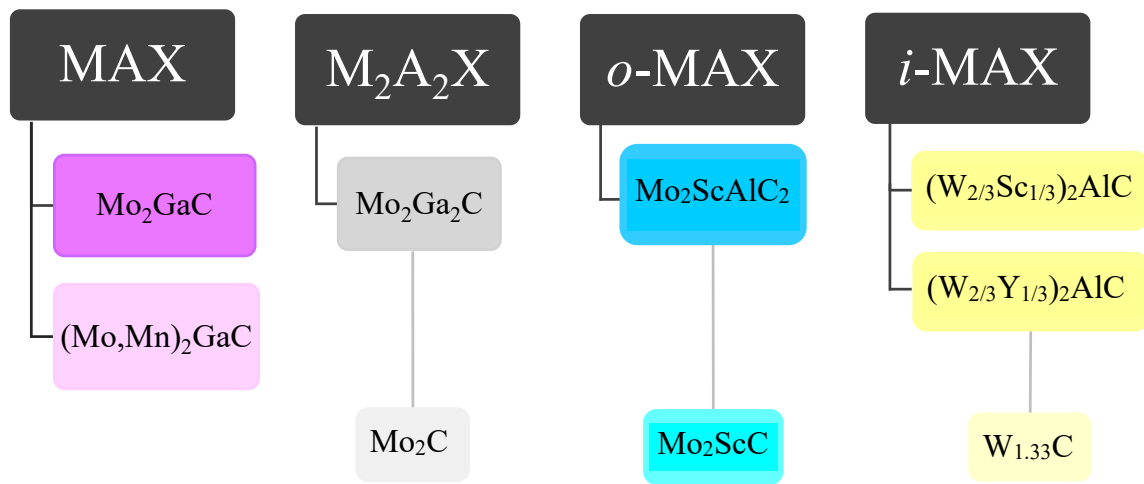

Figure 25 Summary chart showing the systems reported in this thesis.

The aim of this work has been to explore novel compositions of atomically laminated materials (MAX phases) as well as their 2D derivatives (MXene compounds), see figure 25, and study their properties and potential for various applications. The samples were synthesized employing two different approaches; thin film synthesis, where a direct current magnetron sputtering system was used, and bulk synthesis, where a pressureless sintering process was applied to produce the powder samples. The materials systems chosen for investigation were to a large extent motived by theoretical predictions, performed within the projects or found in the literature.

In my first study, I synthesized the first Mo-containing $\mathrm{MAX}$ phase, $\mathrm{Mo}_{2} \mathrm{GaC}$, in thin film form. High structural quality was attained, which is essential for evaluation of transport properties. Most importantly, the synthesis realized a sample free from other competing phases in the Mo-Ga-C system which are superconducting, containing only small traces of one of the most competing phases within the system, $\mathrm{Mo}_{3} \mathrm{Ga}$. The temperature dependence of the electrical resistivity of the thin films showed a critical temperature of $\sim 7 \mathrm{~K}$, which was further supported through a magnetic field dependence of the resistivity (parallel to the film plane), and an indicated decrease of the critical temperature upon elevated field strength. Based on the results, superconductivity was suggested, however further experiments are needed for a definite 
conclusion. Still, overcoming the challenges associated with thin film synthesis (sputtering) from a liquid Ga-target, is something that can be applied to synthesis of other Ga-containing phases.

In paper II, we discovered a new Mo-containing MAX related material, $\mathrm{Mo}_{2} \mathrm{Ga}_{2} \mathrm{C}$, where $\mathrm{Mo}_{2} \mathrm{C}$ blocks are interleaved with a Ga double-layer instead of a monolayer. Since, the other two MAX stoichiometries, i.e., 312 and 413 MAX phases within the Mo-Ga-C system are unstable according to the theoretical calculations, this discovery is of great importance. First of all because it is the second Mo-containing MAX phase (or MAX phase like material), and second because it realizes production of a $\mathrm{Mo}_{2} \mathrm{C}$ MXene, see below.

In paper III, I report synthesis of a 2D transition metal carbide, $\mathrm{Mo}_{2} \mathrm{C}$, which is the first MXene compound including Mo as the $M$-element, and the first MXene obtained from selective etching of Ga layers instead of Al, which is the etched element for all other MXenes produced to date. This means realization of a new MXene with novel properties, in turn opening a field of research on this material. Furthermore, it suggests a path for future synthesis of MXenes of new compositions by etching of $\mathrm{Ga}$.

Previously reported magnetic MAX phases are based on $\mathrm{Cr} / \mathrm{Mn}$ as the $M$-elements. In paper IV, I focused on experimental synthesis and characterization of a new magnetic MAX phase alloy, based on Mo/Mn on the $M$ site. This is the first study going beyond other magnetic MAX phase alloys which all includes $\mathrm{Cr}$ and/or Mn, exploring what magnetic behavior is realized in a non-magnetic MAX phase $\left(\mathrm{Mo}_{2} \mathrm{GaC}\right)$ by incorporation of $\mathrm{Mn}$ atoms. A magnetic response up to $300 \mathrm{~K}$, including a ferromagnetic component up to $150 \mathrm{~K}$ was obtained from VSM. The remanence and $5 \mathrm{~T}$ magnetic moment of the films at $3 \mathrm{~K}$ were identified as $\sim 0.35$ and $\sim 0.66$ Bohr magneton per metal atom, with a coercive field of about $0.06 \mathrm{~T}$ which is the highest value of all magnetic MAX phases synthesized to date. This somewhat unexpected results motivate further exploration of other combinations of MAX phase elements together with Mn, for fundamental understanding and potential tuning of the magnetic properties. 
In paper $\mathrm{V}$, I realized a new out-of-plane chemically ordered $\mathrm{MAX}$ phase, $\mathrm{Mo}_{2} \mathrm{ScAlC}_{2}$, and its $2 \mathrm{D}$ derivative, $\mathrm{Mo}_{2} \mathrm{ScC}$. These were the first experimentally verified Sc-containing MAX and MXene compounds. Continuing incorporation of new elements into MAX phases, I synthesized and characterized the first $\mathrm{W}$-containing $i$-MAX phases; $\left(\mathrm{W}_{2 / 3} \mathrm{Sc}_{1 / 3}\right)_{2} \mathrm{AlC}$ and $\left(\mathrm{W}_{2 / 3} \mathrm{Y}_{1 / 3}\right)_{2} \mathrm{AlC}$, followed by their $2 \mathrm{D}$ counterpart; $\mathrm{W}_{1.33} \mathrm{C}$ MXene, reported in paper VI. According to theoretical calculations, W-containing MAX phases are unstable, thus, alloying and formation of an $i$-MAX phase is the path for realization of $\mathrm{W}$-based phases in 3D and 2D. Further, W-based compounds are of great importance as promising materials for realization of topological insulators and effective catalyst materials, which makes this is a discovery highly motivating for further research.

Altogether, I have within my thesis work realized 6 novel MAX phases (or related materials), and 4 novel MXenes. The thesis shows the strength of the combination of theoretical predictions and verifying materials synthesis, and the new materials will likely be the topic of extensive future investigations with respect to fundamentals as well as potential for various applications. 



\section{LIST OF REFERENCES}

[1] M.W. Barsoum, MAX Phases: Properties of Machinable Ternary Carbides and Nitrides, Wiley-VCH, Weinheim, 2013.

[2] H. Nowotny, Strukturchemie einiger verbindungen der übergangsmetalle mit den elementen $\mathrm{C}, \mathrm{Si}, \mathrm{Ge}, \mathrm{Sn}$, Prog. Solid. State. Chem, 5 (1971) 27-70.

[3] W. Jeitschko, H. Nowotny, F. Benesovsky, Kohlenstoffhaltige ternäre Verbindungen (V-Ge-C, Nb-Ga-C, TaGa-C, Ta-Ge-C, Cr-Ga-C und Cr-Ge-C), Monatsh Chem. 94(5) (1963) 844-850.

[4] M. W. Barsoum, T. El-Raghy, Synthesis and Characterization of a Remarkable Ceramic: $\mathrm{Ti}_{3} \mathrm{SiC}_{2}, \mathrm{~J} . \mathrm{Am}$. Ceram. Soc 79 (1996).

[5] H.W. K. Sakamaki, H. Nozaki, Y. Onuki, M. Kawai, Carbosulfide superconductor, Solid State Commun. 112 (1999) 323-237.

[6] A.D. Bortolozo, O.H. Sant'Anna, M.S. da Luz, C.A.M. dos Santos, A.S. Pereira, K.S. Trentin, A.J.S. Machado, Superconductivity in the $\mathrm{Nb}_{2} \mathrm{SnC}$ compound, Solid State Commun. 139(2) (2006) 57-59.

[7] S. Lofland, J. Hettinger, T. Meehan, A. Bryan, P. Finkel, S. Gupta, M. Barsoum, G. Hug, Electron-phonon coupling in $\mathrm{M}_{\mathrm{n}+1} \mathrm{AX}_{\mathrm{n}}$-phase carbides, Physical Review B 74(17) (2006).

[8] A.D. Bortolozo, Z. Fisk, O.H. Sant'Anna, C.A.M.d. Santos, A.J.S. Machado, Superconductivity in $\mathrm{Nb}_{2} \mathrm{InC}$, Physica C-Superconductivity and Its Applications 469(7-8) (2009) 256-258.

[9] A.D. Bortolozo, O.H. Sant'Anna, C.A.M. dos Santos, A.J.S. Machado, Superconductivity in the hexagonallayered nanolaminates $\mathrm{Ti}_{2} \mathrm{InC}$ compound, Solid State Communications 144(10-11) (2007) 419-421.

[10] A.D. Bortolozo, G. Serrano, A. Serquis, D. Rodrigues, C.A.M. dos Santos, Z. Fisk, A.J.S. Machado, Superconductivity at 7.3 K in $\mathrm{Ti}_{2} \mathrm{InN}$, Solid State Communications $150(29-30)$ (2010) 1364-1366.

[11] L.E. Toth, High superconducting transition temperatures in the molybdenum carbide family of compounds, J. Less-Common Met. 13 (1967) 127-129.

[12] A.S. Ingason, A. Mockute, M. Dahlqvist, F. Magnus, S. Olafsson, U.B. Arnalds, B. Alling, I.A. Abrikosov, B. Hjörvarsson, P.O.Å. Persson, J. Rosen, Magnetic Self-Organized Atomic Laminate from First Principles and Thin Film Synthesis, Phys. Rev. Lett. 110(19) (2013) 195502-5.

[13] M. Naguib, M. Kurtoglu, V. Presser, J. Lu, J. Niu, M. Heon, L. Hultman, Y. Gogotsi, M.W. Barsoum, Twodimensional nanocrystals produced by exfoliation of Ti3 AlC2, Adv Mater 23(37) (2011) 4248-53.

[14] Z. Liu, L. Zheng, L. Sun, Y. Qian, J. Wang, M. Li, G.P. Bei, $\left(\mathrm{Cr}_{2 / 3} \mathrm{Ti}_{1 / 3}\right)_{3} \mathrm{AlC}_{2}$ and $\left(\mathrm{Cr}_{5 / 8} \mathrm{Ti}_{3 / 8}\right)_{4} \mathrm{AlC}$ : New MAX-phase Compounds in Ti-Cr-Al-C System, J. Am. Ceram. Soc. 97(1) (2014) 67-69.

[15] Q. Tao, M. Dahlqvist, J. Lu, S. Kota, R. Meshkian, J. Halim, J. Palisaitis, L. Hultman, M.W. Barsoum, P.O.A. Persson, J. Rosen, Two-dimensional $\mathrm{Mo}_{1.33} \mathrm{C}$ MXene with divacancy ordering prepared from parent 3D laminate with in-plane chemical ordering, Nat Commun 8 (2017) 14949.

[16] H. Weng, A. Ranjbar, Y. Liang, Z. Song, M. Khazaei, S. Yunoki, M. Arai, Y. Kawazoe, Z. Fang, X. Dai, Large-gap two-dimensional topological insulator in oxygen functionalized MXene, Physical Review B 92(7) (2015).

[17] M.W. Barsoum, T. El-Raghy, The MAX Phases: Unique New Carbide and Nitride Materials, Am. Sci. 89 (2001) 334-343. 
[18] P. Eklund, M. Beckers, U. Jansson, H. Högberg, L. Hultman, The $M_{n+1} A X_{n}$ phases: Materials science and thin-film processing, Thin Solid Films 518(8) (2010) 1851-1878.

[19] M. Radovic, M.W. Barsoum, MAX phases: Bridging the gap between metals and ceramics, Am. Ceram. Sci. Bull. 92(3) (2013) 20-27.

[20] M. W. Barsoum, M. Radovic, Elastic and Mechanical Properties of the MAX Phases, Annu. Rev. Mater. Res. 41(1) (2011) 195-227.

[21] J.P. Palmquist, S. Li, P.O.Å. Persson, J. Emmerlich, O. Wilhelmsson, H. Högberg, M.I. Katsnelson, B. Johansson, R. Ahuja, O. Eriksson, L. Hultman, U. Jansson, $\mathrm{M}_{\mathrm{n}+1} \mathrm{AX}_{\mathrm{n}}$ phases in the Ti-Si-C system studied by thin-film synthesis and ab initio calculations, Phys. Rev. B 70(16) (2004).

[22] C. Walter, D.P. Sigumonrong, T. El-Raghy, J.M. Schneider, Towards large area deposition of $\mathrm{Cr}_{2} \mathrm{AlC}_{\mathrm{C}}$ steel, Thin Solid Films 515(2) (2006) 389-393.

[23] O. Wilhelmsson, P. Eklund, H. Högberg, L. Hultman, U. Jansson, Structural, electrical and mechanical characterization of magnetron-sputtered V-Ge-C thin films, Acta Mater. 56(11) (2008) 2563-2569.

[24] M.W. Barsouma, T. El-Raghya, C.J. Rawnb, W.D. Porterb, H. Wangb, E.A. Payzantb, C.R. Hubbardb, Thermal properties of $\mathrm{Ti}_{3} \mathrm{SiC}_{2}$, J. Phys. Chem. Solids 60 (1999) 429-439.

[25] R. Radhakrishnan, J.J. Williams, M. Akinc, Synthesis and high-temperature stability of $\mathrm{Ti}_{3} \mathrm{SiC}_{2}$, J. Alloys Compnd. 285 (1999) 85-88.

[26] M.W. Barsoum, I. Salama, T. El-Raghy, J. Golczewski, W.D. Porter, H. Wang, H.J. Seifert, F. Aldinger, Thermal and Electrical Properties of $\mathrm{Nb}_{2} \mathrm{AlC},(\mathrm{Ti}, \mathrm{Nb})_{2} \mathrm{AlC}$ and $\mathrm{Ti}_{2} \mathrm{AlC}$, Metal. and Mater. Trans. A 33A (2002) 2775-2779.

[27] H. Yang, B. Manoun, R.T. Downs, A. Ganguly, M.W. Barsoum, Crystal chemistry of layered carbide, $\mathrm{Ti}_{3}\left(\mathrm{Si}_{0.43} \mathrm{Ge}_{0.57}\right) \mathrm{C}_{2}$, J. Phys. and Chem. of Solids 67(12) (2006) 2512-2516.

[28] B. Manoun, S.K. Saxena, G. Hug, A. Ganguly, E.N. Hoffman, M.W. Barsoum, Synthesis and compressibility of $\mathrm{Ti}_{3}\left(\mathrm{Al}, \mathrm{Sn}_{0.2}\right) \mathrm{C}_{2}$ and $\mathrm{Ti}_{3} \mathrm{Al}\left(\mathrm{C}_{0.5}, \mathrm{~N}_{0.5}\right)_{2}$, J. Appl. Phys. 101(11) (2007) 113523.

[29] M. Naguib, G.W. Bentzel, J. Shah, J. Halim, E.N. Caspi, J. Lu, L. Hultman, M.W. Barsoum, New Solid Solution MAX Phases: $\left(\mathrm{Ti}_{0.5}, \mathrm{~V}_{0.5}\right)_{3} \mathrm{AlC}_{2},\left(\mathrm{Nb}_{0.5}, \mathrm{~V}_{0.5}\right)_{2} \mathrm{AlC},\left(\mathrm{Nb}_{0.5}, \mathrm{~V}_{0.5}\right)_{4} \mathrm{AlC}_{3}$ and $\left(\mathrm{Nb}_{0.8}, \mathrm{Zr}_{0.2}\right)_{2} \mathrm{AlC}$, Mater. Res. Lett. 2(4) (2014) 233-240.

[30] F.L. Meng, Y.C. Zhou, J.Y. Wang, Strengthening of $\mathrm{Ti}_{2} \mathrm{AlC}$ by substituting Ti with V, Scr. Mater. 53(12) (2005) 1369-1372.

[31] J. Rosen, M. Dahlqvist, S.I. Simak, D.R. McKenzie, M.M.M. Bilek, Oxygen incorporation in Ti ${ }_{2}$ AlC: Tuning of anisotropic conductivity, Appl. Phys. Lett. 97(7) (2010) 073103-3.

[32] A. Mockute, M. Dahlqvist, L. Hultman, P.O.Å. Persson, J. Rosen, Oxygen incorporation in Ti $2 \mathrm{AlC}_{\mathrm{C}}$ thin films studied by electron energy loss spectroscopy and ab initio calculations, J. Mater. Sci. 48(10) (2013) 3686-3691.

[33] M.W. Barsoum, M. Ali, T. EL-Raghy, Processing and Characterization of $\mathrm{Ti}_{2} \mathrm{AlC}, \mathrm{Ti}_{2} \mathrm{AlN}$, and $\mathrm{Ti}_{2} \mathrm{AlC}_{0.5} \mathrm{~N}_{0.5}$, Metal. and Mater. Trans. A 31A (2000) 1857-1865.

[34] A. Petruhins, A. Ingason, J. Lu, F. Magnus, S. Olafsson, J. Rosen, Synthesis and characterization of magnetic $\left(\mathrm{Cr}_{0.5} \mathrm{Mn}_{0.5}\right)_{2} \mathrm{GaC}$ thin films, J. Mater. Sci. 50(13) (2015) 4495-4502.

[35] A. Mockute, M. Dahlqvist, J. Emmerlich, L. Hultman, J. Schneider, P.O.Å. Persson, J. Rosen, Synthesis and ab initio calculations of nanolaminated (Cr,Mn) 2 AlC compounds, Phys. Rev. B 87(9) (2013) 094113-4.

[36] D.v. Delft, P. Kes, The discovery of superconductivity, Phys.Today S-0031-9228-1009-020-4 (2010). 
[37] J.R. Hull, Applications of high-temperature superconductors in power technology, Rep. Prog. Phys. 66 (2003) 1865-1886.

[38] S. Kang, A. Goyal, J. Li, A.A. Gapud, P.M. Martin, L. Heatherly, J.R. Thompson, D.K. Christen, F.A. List, M. Paranthaman, D.F. Lee, High-Performance High- $\mathrm{T}_{\mathrm{c}}$ uperconducting Wires, Science 311 (2006).

[39] S.S. Parkin, C. Kaiser, A. Panchula, P.M. Rice, B. Hughes, M. Samant, S.H. Yang, Giant tunnelling magnetoresistance at room temperature with MgO (100) tunnel barriers, Nat. Mater. 3(12) (2004) 862-7.

[40] S.A. Wolf, D.D. Awschalom, R.A. Buhrman, J.M. Daughton, S.v. Molnar, M.L. Roukes, A.Y. Chtchelkanova, D.M. Treger, Spintronics: a spin-based electronics vision for the future, Science 294(5546) (2001) 1488-95.

[41] W. Luo, R. Ahuja, Magnetic $\mathrm{Fe}_{(\mathrm{n}+1)} \mathrm{AC}_{(\mathrm{n})}(\mathrm{n}=1,2,3$, and $\mathrm{A}=\mathrm{Al}, \mathrm{Si}$, Ge) phases: from ab initio theory, J. Phys. Condens. Matter 20(6) (2008) 064217.

[42] M. Dahlqvist, B. Alling, I.A. Abrikosov, J. Rosen, Magnetic nanoscale laminates with tunable exchange coupling from first principles, Phys. Rev. B 84(22) (2011) 220403-1.

[43] A. Mockute, P.O.Å. Persson, F. Magnus, A.S. Ingason, S. Olafsson, L. Hultman, J. Rosen, Synthesis and characterization of arc deposited magnetic (Cr,Mn) ${ }_{2}$ AlC MAX phase films, Phys. Status Solidi (RRL) 8(5) (2014) 420-423.

[44] A. Mockute, J. Lu, E.J. Moon, M. Yan, B. Anasori, S.J. May, M.W. Barsoum, J. Rosen, Solid Solubility and Magnetism upon Mn Incorporation in the Bulk Ternary Carbides $\mathrm{Cr}_{2} \mathrm{AlC}$ and $\mathrm{Cr}_{2} \mathrm{GaC}$, Mater. Res. Lett. 3(1) (2014) 16-22.

[45] A. Mockute, M. Dahlqvist, J. Emmerlich, L. Hultman, J. Schneider, P.O.Å. Persson, J. Rosen, Synthesis and ab initio calculations of nanolaminated (Cr,Mn) ${ }_{2} \mathrm{AlC}$ compounds, Phys. Rev. B 87(9) (2013) 094113.

[46] Z. Liu, T. Waki, Y. Tabata, H. Nakamura, Mn-doping-induced itinerant-electron ferromagnetism inCr $\mathrm{GeC}_{2}$ Phys. Rev. B 89(5) (2014).

[47] A.S. Ingason, A. Petruhins, M. Dahlqvist, F. Magnus, A. Mockute, B. Alling, L. Hultman, I.A. Abrikosov, P.O.Å. Persson, J. Rosen, A Nanolaminated Magnetic Phase: Mn2GaC, Materials Research Letters 2(2) (2013) 89-93.

[48] I.P. Novoselova, A. Petruhins, U. Wiedwald, A.S. Ingason, T. Hase, F. Magnus, V. Kapaklis, J. Palisaitis, M. Spasova, M. Farle, J. Rosen, R. Salikhov, Large uniaxial magnetostriction with sign inversion at the first order phase transition in the nanolaminated $\mathrm{Mn}_{2} \mathrm{GaC}$ MAX phase, Sci Rep 8(1) (2018) 2637.

[49] E.a.N. Caspi, P. Chartier, F. Porcher, F. Damay, T. Cabioc'h, Ordering of (Cr,V) Layers in Nanolamellar $\left(\mathrm{Cr}_{0.5} \mathrm{~V}_{0.5}\right)_{\mathrm{n}+1} \mathrm{AlC}_{\mathrm{n}}$ Compounds, Mater. Res. Lett. 3(2) (2014) 100-106.

[50] B. Anasori, M. Dahlqvist, J. Halim, E.J. Moon, J. Lu, B.C. Hosler, E.a.N. Caspi, S.J. May, L. Hultman, P. Eklund, J. Rosén, M.W. Barsoum, Experimental and theoretical characterization of ordered MAX phases $\mathrm{Mo}_{2} \mathrm{TiAlC}_{2}$ and $\mathrm{Mo}_{2} \mathrm{Ti}_{2} \mathrm{AlC}_{3}$, J. Appl. Phys. 118(9) (2015) 094304-14.

[51] M. Dahlqvist, J. Rosen, Order and disorder in quaternary atomic laminates from first-principles calculations, Phys Chem Chem Phys 17(47) (2015) 31810-21.

[52] L. E. Toth, W. Jetschko, C.M. Yen, The superconducting and nitrides behavior of several complex carbides, J. Less comm. metals 10 (1966) 29-32.

[53] M. Dahlqvist, J. Lu, R. Meshkian, Q. Tao, L. Hultman, J. Rosen, Prediction and synthesis of a family of atomic laminate phases with Kagome-like and in-plane chemical ordering, Sci Adv 3(7) (2017) e1700642. 
[54] J. Lu, A. Thore, R. Meshkian, Q. Tao, L. Hultman, J. Rosen, Theoretical and Experimental Exploration of a Novel In-Plane Chemically Ordered $\left(\mathrm{Cr}_{2 / 3} \mathrm{M}_{1 / 3}\right)_{2} \mathrm{AlC}$ i-MAX Phase with $\mathrm{M}=\mathrm{Sc}$ and $\mathrm{Y}$, Crystal Growth \& Design (2017).

[55] C. Eames, M.S. Islam, Ion intercalation into two-dimensional transition-metal carbides: global screening for new high-capacity battery materials, J. Am. Chem. Soc. 136(46) (2014) 16270-6.

[56] M. Naguib, J. Come, B. Dyatkin, V. Presser, P.-L. Taberna, P. Simon, M.W. Barsoum, Y. Gogotsi, MXene: a promising transition metal carbide anode for lithium-ion batteries, Electrochem. Commun. 16(1) (2012) 61-64.

[57] M. Naguib, J. Halim, J. Lu, K.M. Cook, L. Hultman, Y. Gogotsi, M.W. Barsoum, New two-dimensional niobium and vanadium carbides as promising materials for Li-ion batteries, J. Am. Chem. Soc. 135(43) (2013) 15966-9.

[58] Q. Tang, Z. Zhou, P. Shen, Are MXenes promising anode materials for Li ion batteries? Computational studies on electronic properties and $\mathrm{Li}$ storage capability of $\mathrm{Ti}_{3} \mathrm{C}_{2}$ and $\mathrm{Ti}_{3} \mathrm{C}_{2} \mathrm{X}_{2}(\mathrm{X}=\mathrm{F}, \mathrm{OH})$ monolayer, J. Am. Chem. Soc. 134(40) (2012) 16909-16.

[59] J. Halim, S. Kota, M.R. Lukatskaya, M. Naguib, M.-Q. Zhao, E.J. Moon, J. Pitock, J. Nanda, S.J. May, Y. Gogotsi, M.W. Barsoum, Synthesis and Characterization of 2D Molybdenum Carbide (MXene), Advanced Func. Mater. 26(18) (2016) 3118-3127.

[60] B. Anasori, Y. Xie, M. Beidaghi, J. Lu, B. C. Hosler, L. Hultman, P. R. C. Kent, Y. Gogotsi, M. W. Barsoum, Two-Dimensional, Ordered, Double Transition Metal Carbide (MXene), J. Am. Chem. Soc. Nano 9 (2015) 95079516.

[61] M. Ghidiu, M.R. Lukatskaya, M.-Q. Zhao, Y. Gogotsi, M.W. Barsoum, Conductive two-dimensional titanium carbide 'clay' with high volumetric capacitance, Nature 516(7529) (2014) 78-81.

[62] Zheng Linga, Chang E. Rena, Meng-Qiang Zhaoa, Jian Yanga, James M. Giammarcoa, Jieshan Qiuc, Michel W. Barsouma, Y. Gogotsi, Flexible and conductive MXene films and nanocomposites with high capacitance, 111 (2014) 16676-16681.

[63] Y. Liu, H. Xiao, W.A. Goddard, 3rd, Schottky-Barrier-Free Contacts with Two-Dimensional Semiconductors by Surface-Engineered MXenes, J. Am. Chem. Soc. 138(49) (2016) 15853-15856.

[64] H. Li, C. Tsai, A.L. Koh, L. Cai, A.W. Contryman, A.H. Fragapane, J. Zhao, H.S. Han, H.C. Manoharan, F. Abild-Pedersen, J.K. Norskov, X. Zheng, Corrigendum: Activating and optimizing $\mathrm{MoS}_{2}$ basal planes for hydrogen evolution through the formation of strained sulphur vacancies, Nat. Mater. 15(3) (2016) 364.

[65] T. Georgiou, R. Jalil, B.D. Belle, L. Britnell, R.V. Gorbachev, S.V. Morozov, Y.J. Kim, A. Gholinia, S.J. Haigh, O. Makarovsky, L. Eaves, L.A. Ponomarenko, A.K. Geim, K.S. Novoselov, A. Mishchenko, Vertical fieldeffect transistor based on graphene-WS $\mathrm{W}_{2}$ heterostructures for flexible and transparent electronics, Nat. Nanotechnol 8(2) (2013) 100-3.

[66] A. Allain, A. Kis, Electron and Hole Mobilities in Single-Layer WSe ${ }_{2}$, ACS Nano 8 (2014) 7180-7185.

[67] H. Fang, S. Chuang, T.C. Chang, K. Takei, T. Takahashi, A. Javey, High-performance single layered WSe(2) p-FETs with chemically doped contacts, Nano Lett. 12(7) (2012) 3788-92.

[68] J. Halim, M.R. Lukatskaya, K.M. Cook, J. Lu, C.R. Smith, L.A. Naslund, S.J. May, L. Hultman, Y. Gogotsi, P. Eklund, M.W. Barsoum, Transparent Conductive Two-Dimensional Titanium Carbide Epitaxial Thin Films, J. Am. Chem. Soc. 26(7) (2014) 2374-2381. 
[69] M. Naguib, O. Mashtalir, J. Carle, V. Presser, J. Lu, L. Hultman, Y. Gogotsi, M.W. Barsoum, TwoDimensional Transition Metal Carbides, J. Am. Chem. Soc. 6(2) (2012) 1322-1331.

[70] M. Naguib, M. Kurtoglu, V. Presser, J. Lu, J. Niu, M. Heon, L. Hultman, Y. Gogotsi, M.W. Barsoum, Twodimensional nanocrystals produced by exfoliation of $\mathrm{Ti}_{3} \mathrm{AlC}_{2}$, Adv. Mater. 23(37) (2011) 4248-53.

[71] R. Meshkian, L.-Å. Näslund, J. Halim, J. Lu, M.W. Barsoum, J. Rosen, Synthesis of two-dimensional molybdenum carbide, $\mathrm{Mo}_{2} \mathrm{C}$, from the gallium based atomic laminate $\mathrm{Mo}_{2} \mathrm{Ga}_{2} \mathrm{C}$, Scripta Mater. 108 (2015) 147150 .

[72] Babak Anasori, Yu Xie, Majid Beidaghi, Jun Lu, Brian C. Hosler, Lars Hultman, Paul R. C. Kent, Yury Gogotsi, M.W. Barsoum, Two-Dimensional, Ordered, Double Transition Metals Carbides (MXenes), ACS Nano 9(10) (2015) 9507-9516.

[73] O. Mashtalir, M. Naguib, V.N. Mochalin, Y. Dall'Agnese, M. Heon, M.W. Barsoum, Y. Gogotsi, Intercalation and delamination of layered carbides and carbonitrides, Nat. Commun. 4 (2013) 1716.

[74] Mohammad Khazaei, Ahmad Ranjbar, Masao Arai, Taizo Sasaki, S. Yunoki, Electronic properties and applications ofMXenes: a theoretical review, Condenced Material Scienece (2017).

[75] I.R. Shein, A.L. Ivanovskii, Graphene-like titanium carbides and nitrides $\mathrm{Ti}_{n+1} \mathrm{C}_{n}, \mathrm{Ti}_{\mathrm{n}+1} \mathrm{~N}_{\mathrm{n}}(\mathrm{n}=1,2$, and 3) from de-intercalated MAX phases: First-principles probing of their structural, electronic properties and relative stability, Comput. Mater. Sci. 65 (2012) 104-114.

[76] Q. Tang, Z. Zhou, P. Shen, Are MXenes promising anode materials for Li ion batteries? Computational studies on electronic properties and $\mathrm{Li}$ storage capability of $\mathrm{Ti}_{3} \mathrm{C}_{2}$ and $\mathrm{Ti}_{3} \mathrm{C}_{2} \mathrm{X}_{2}(\mathrm{X}=\mathrm{F}, \mathrm{OH})$ monolayer, J. Am. Chem. Soc. 134(40) (2012) 16909-16.

[77] Q. Tang, Z. Zhou, Graphene-analogous low-dimensional materials, Progress in Materials Science 58(8) (2013) 1244-1315.

[78] M. Khazaei, M. Arai, T. Sasaki, C.-Y. Chung, N.S. Venkataramanan, M. Estili, Y. Sakka, Y. Kawazoe, Novel Electronic and Magnetic Properties of Two-Dimensional Transition Metal Carbides and Nitrides, Adv. Func. Mater. 23(17) (2013) 2185-2192.

[79] Y. Xie, M. Naguib, V.N. Mochalin, M.W. Barsoum, Y. Gogotsi, X. Yu, K.W. Nam, X.Q. Yang, A.I. Kolesnikov, P.R. Kent, Role of surface structure on Li-ion energy storage capacity of two-dimensional transitionmetal carbides, J. Am. Chem. Soc. 136(17) (2014) 6385-94.

[80] A. Lipatov, M. Alhabeb, M.R. Lukatskaya, A. Boson, Y. Gogotsi, A. Sinitskii, Effect of Synthesis on Quality, Electronic Properties and Environmental Stability of Individual Monolayer $\mathrm{Ti}_{3} \mathrm{C}_{2}$ MXene Flakes, Adv. Elec. Mater. 2(12) (2016).

[81] X. Sang, Y. Xie, M.W. Lin, M. Alhabeb, K.L. Van Aken, Y. Gogotsi, P.R. Kent, K. Xiao, R.R. Unocic, Atomic Defects in Monolayer Titanium Carbide $\left(\mathrm{Ti}_{3} \mathrm{C}_{2} \mathrm{~T}_{\mathrm{x}}\right)$ MXene, ACS Nano (2016).

[82] M. Khazaei, M. Arai, T. Sasaki, M. Estili, Y. Sakka, The effect of the interlayer element on the exfoliation of layered Mo2AC $\left(\mathrm{A}=\mathrm{Al}, \mathrm{Si}, \mathrm{P}, \mathrm{Ga}, \mathrm{Ge}, \mathrm{As}\right.$ or In) MAX phases into two-dimensional $\mathrm{Mo}_{2} \mathrm{C}$ nanosheets, Sci. Technol. Adv. Mater. 15(1) (2014) 014208.

[83] M. Naguib, R.R. Unocic, B.L. Armstrong, J. Nanda, Large-scale delamination of multi-layers transition metal carbides and carbonitrides "MXenes", Dalton Trans 44(20) (2015) 9353-8. 
[84] B. Anasori, C. Shi, E.J. Moon, Y. Xie, C.A. Voigt, P.R.C. Kent, S.J. May, S.J.L. Billinge, M.W. Barsoum, Y. Gogotsi, Control of electronic properties of 2D carbides (MXenes) by manipulating their transition metal layers, Nanoscale Horizons 1(3) (2016) 227-234.

[85] M.R. Lukatskaya, O. Mashtalir, C.E. Ren, Y. Dall'Agnese, P. Rozier, P.L. Taberna, M. Naguib, P. Simon, M.W. Barsoum, Y. Gogotsi, Cation intercalation and high volumetric capacitance of two-dimensional titanium carbide, Science 341(6153) (2013) 1502-5.

[86] Faisal Shahzad, Mohamed Alhabeb, Christine B. Hatter, Babak Anasori, Soon Man Hong, Chong Min Koo, Y. Gogotsi, Electromagnetic interference shielding with 2D transition metal carbides (MXenes), Mater. Sci. 353 (2016) 1137-1140.

[87] M. Han, X. Yin, H. Wu, Z. Hou, C. Song, X. Li, L. Zhang, L. Cheng, $\mathrm{T}_{\mathrm{i} 3} \mathrm{C}_{2}$ MXenes with Modified Surface for High-Performance Electromagnetic Absorption and Shielding in the X-Band, ACS Appl. Mater. Interfaces 8(32) (2016) 21011-9.

[88] W. Feng, H. Luo, Y. Wang, S. Zeng, L. Deng, X. Zhou, H. Zhang, S. Peng, $\mathrm{Ti}_{3} \mathrm{C}_{2}$ MXene: a promising microwave absorbing material, RSC Advances 8(5) (2018) 2398-2403.

[89] Q. Peng, J. Guo, Q. Zhang, J. Xiang, B. Liu, A. Zhou, R. Liu, Y. Tian, Unique lead adsorption behavior of activated hydroxyl group in two-dimensional titanium carbide, J. Am. Chem. Soc. 136(11) (2014) 4113-6.

[90] L. Wang, L. Yuan, K. Chen, Y. Zhang, Q. Deng, S. Du, Q. Huang, L. Zheng, J. Zhang, Z. Chai, M.W. Barsoum, X. Wang, W. Shi, Loading Actinides in Multilayered Structures for Nuclear Waste Treatment: The First Case Study of Uranium Capture with Vanadium Carbide MXene, ACS Appl. Mater. Interfaces 8(25) (2016) 16396-403.

[91] Y.J. Zhang, J.H. Lan, L. Wang, Q.Y. Wu, C.Z. Wang, T. Bo, Z.F. Chai, W.Q. Shi, Adsorption of uranyl species on hydroxylated titanium carbide nanosheet: A first-principles study, J. Hazard Mater 308 (2016) 402-10. [92] C. Peng, X. Yang, Y. Li, H. Yu, H. Wang, F. Peng, Hybrids of Two-Dimensional $\mathrm{Ti}_{3} \mathrm{C}_{2}$ and $\mathrm{TiO}_{2}$ Exposing $\{001\}$ Facets toward Enhanced Photocatalytic Activity, ACS Appl. Mater. Interfaces 8(9) (2016) 6051-60.

[93] F. Wang, C. Yang, M. Duan, Y. Tang, J. Zhu, $\mathrm{TiO}_{2}$ nanoparticle modified organ-like $\mathrm{Ti}_{3} \mathrm{C}_{2} \mathrm{MXene}$ nanocomposite encapsulating hemoglobin for a mediator-free biosensor with excellent performances, Biosens Bioelectron 74 (2015) 1022-8.

[94] B. Xu, M. Zhu, W. Zhang, X. Zhen, Z. Pei, Q. Xue, C. Zhi, P. Shi, Ultrathin MXene-Micropattern-Based Field-Effect Transistor for Probing Neural Activity, Adv. Mater. 28(17) (2016) 3333-9.

[95] K. Rasool, M. Helal, A. Ali, C.E. Ren, Y. Gogotsi, K.A. Mahmoud, Antibacterial Activity of $\mathrm{Ti}_{(3)} \mathrm{C}_{(2)} \mathrm{T}_{\mathrm{x}}$ MXene, ACS Nano 10(3) (2016) 3674-84.

[96] J. Yang, B. Chen, H. Song, H. Tang, C. Li, Synthesis, characterization, and tribological properties of twodimensional $\mathrm{Ti}_{3} \mathrm{C}_{2}$, Crys. Res. and Tech. 49(11) (2014) 926-932.

[97] X. Zhang, M. Xue, X. Yang, Z. Wang, G. Luo, Z. Huang, X. Sui, C. Li, Preparation and tribological properties of $\mathrm{Ti}_{3} \mathrm{C}_{2}(\mathrm{OH})_{2}$ nanosheets as additives in base oil, RSC Advances 5(4) (2015) 2762-2767.

[98] M. Khazaei, M. Arai, M. Sasaki, T. Estili, M. Estili, Y. Sakka, Two-dimensional molybdenum carbides: potential thermoelectric materials of the MXene family, Phys. Chem. Chem. Phys. : PCCP 16(17) (2014) 7841-9. [99] A.W. Robertson, C.S. Allen, Y.A. Wu, K. He, J. Olivier, J. Neethling, A.I. Kirkland, J.H. Warner, Spatial control of defect creation in graphene at the nanoscale, Nature communications 3 (2012) 1144. 
[100] Y. Liu, H. Xiao, W.A. Goddard, 3rd, Two-Dimensional Halide Perovskites: Tuning Electronic Activities of Defects, Nano Lett 16(5) (2016) 3335-40.

[101] Z.W. Seh, K.D. Fredrickson, B. Anasori, J. Kibsgaard, A.L. Strickler, M.R. Lukatskaya, Y. Gogotsi, T.F. Jaramillo, A. Vojvodic, Two-Dimensional Molybdenum Carbide (MXene) as an Efficient Electrocatalyst for Hydrogen Evolution, ACS Energy Letters 1(3) (2016) 589-594.

[102] C. Ling, L. Shi, Y. Ouyang, J. Wang, Searching for Highly Active Catalysts for Hydrogen Evolution Reaction Based on O-Terminated MXenes through a Simple Descriptor, Chem. Mater. 28(24) (2016) 9026-9032. [103] J.L. Schroeder, A.S. Ingason, J. Rosén, J. Birch, Beware of poor-quality MgO substrates: A study of MgO substrate quality and its effect on thin film quality, J. Cryst. Growth 420 (2015) 22-31.

[104] H. Högberg, P. Eklund, J. Emmerlich, J. Birch, L. Hultman, Epitaxial Ti 2 GeC, $\mathrm{Ti}_{3} \mathrm{GeC}_{2}$, and $\mathrm{Ti}_{4} \mathrm{GeC}_{3} \mathrm{MAX}-$ phase thin films grown by magnetron sputtering, Journal of Materials Research 20(04) (2011) 779-782.

[105] A.S. Ingason, A. Petruhins, J. Rosen, Toward Structural Optimization of MAX Phases as Epitaxial Thin Films, Mater. Res. Lett. 4(3) (2016) 152-160.

[106] H.M. R1ETVELD, A Profile Refinement Method for Nuclear and Magnetic Structures, J. Appl. Cryst. 2 (1969) 65-71.

[107] J.K. Norskov, T. Bligaard, J. Rossmeisl, C.H. Christensen, Towards the computational design of solid catalysts, Nat Chem 1(1) (2009) 37-46.

[108] J.D. Benck, T.R. Hellstern, J. Kibsgaard, P. Chakthranont, T.F. Jaramillo, Catalyzing the Hydrogen Evolution Reaction (HER) with Molybdenum Sulfide Nanomaterials, ACS Catalysis 4(11) (2014) 3957-3971.

[109] Berit Hinnemann, Poul Georg Moses, Jacob Bonde, Kristina P. Jørgensen, Jane H. Nielsen, Sebastian Horch, Chorkendorff, J.K. Nørskov, Biomimetic Hydrogen Evolution: $\mathrm{MoS}_{2}$ Nanoparticles as Catalyst for Hydrogen Evolution, J. Am. Chem. Soc. 127 (2005) 5308-5309.

[110] D. Voiry, H. Yamaguchi, J. Li, R. Silva, D.C. Alves, T. Fujita, M. Chen, T. Asefa, V.B. Shenoy, G. Eda, M. Chhowalla, Enhanced catalytic activity in strained chemically exfoliated $\mathrm{WS}_{2}$ nanosheets for hydrogen evolution, Nat. Mater. 12(9) (2013) 850-5.

[111] C. Ling, L. Shi, Y. Ouyang, Q. Chen, J. Wang, Transition Metal-Promoted $\mathrm{V}_{2} \mathrm{CO}_{2}$ (MXenes): A New and Highly Active Catalyst for Hydrogen Evolution Reaction, Adv Sci (Weinh) 3(11) (2016) 1600180.

[112] R.M. Martin, Electroni Structure: Basic Theory and Practical Methods, Cambridge University Press, Cambridge 2004.

[113] H.J. Monkhorst, J.D. Pack, Special points for Brillouin-zone integrations, Phys. Rev. B 13(12) (1976) 51885192 .

[114] J. Lundgren, M. Rönnqvist, P. Värbrand, Linjär och ickelinjär optimering, Studentlitteratur, Lund, 2001.

[115] M. Dahlqvist, B. Alling, J. Rosen, Stability trends of MAX phases from first principles, Phys. Rev. B 81(22) (2010).

[116] P. Eklund, M. Dahlqvist, O. Tengstrand, L. Hultman, J. Lu, N. Nedfors, U. Jansson, J. Rosén, Discovery of the Ternary Nanolaminated Compound $\mathrm{Nb}_{2} \mathrm{GeC}$ by a Systematic Theoretical-Experimental Approach, Phys. Rev. Lett. 109(3) (2012).

[117] A. Thore, M. Dahlqvist, B. Alling, J. Rosén, Temperature dependent phase stability of nanolaminated ternaries from first-principles calculations, J. Comput. Mater. Sci 91 (2014) 251-257. 


\section{Papers}

The papers associated with this thesis have been removed for copyright reasons. For more details about these see:

http://urn.kb.se/resolve?urn=urn:nbn:se:liu:diva-148012 